Supporting Information

\title{
Preparation of Hydrophilic Conjugated Microporous Polymers for Efficient Visible Light-driven NADH Regeneration and Photobiocatalytic Formaldehyde Reduction
}

Fang $\operatorname{Lan}^{\dagger}$, Qin Wang $^{\dagger}$, Hui Chen ${ }^{\dagger}{ }^{\ddagger}$, Yi Chen ${ }^{\dagger}$, Yuanyuan Zhang ${ }^{\S}$, Bowen Huang ${ }^{\dagger}$, Hongbo Liü, ${ }^{\dagger}$, Jian Liu*, §, Run Li*,+,

† College of Material Science and Engineering, Hunan University, Hunan, Changsha 410082, China

¥ Hunan Province Key Laboratory for Advanced Carbon Materials and Applied Technology, Hunan University, Hunan, Changsha 410082, China.

$\S$ College of Materials Science and Engineering, Qingdao University of Science and Technology, Qingdao 266042, China.

E-mail: lirun@hnu.edu.cn

E-mail: liujian@qust.edu.cn 


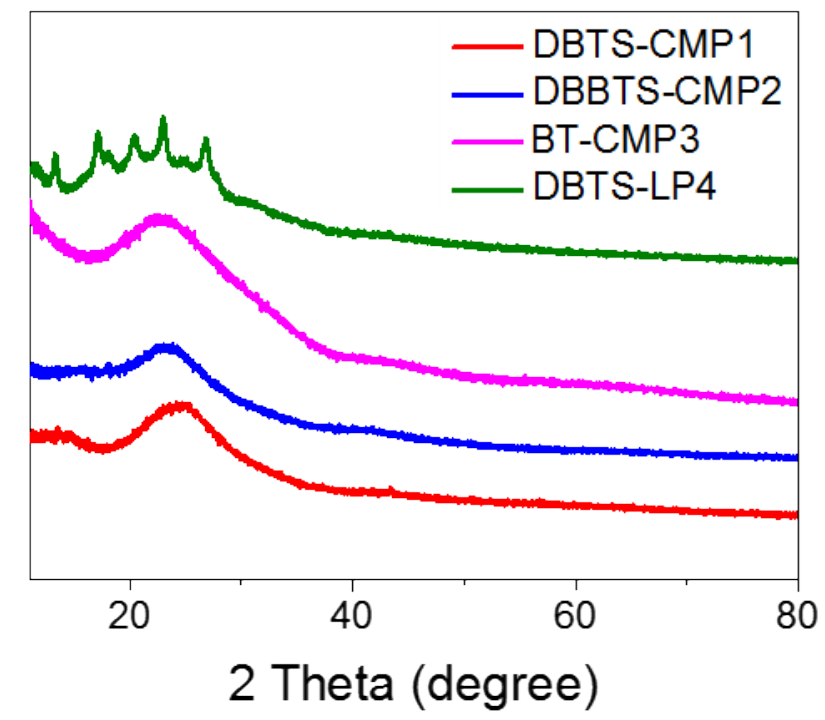

Figure S1. PXRD patterns of DBTS-CMP1, DBBTS-CMP2, BT-CMP3 and DBTS-LP4.

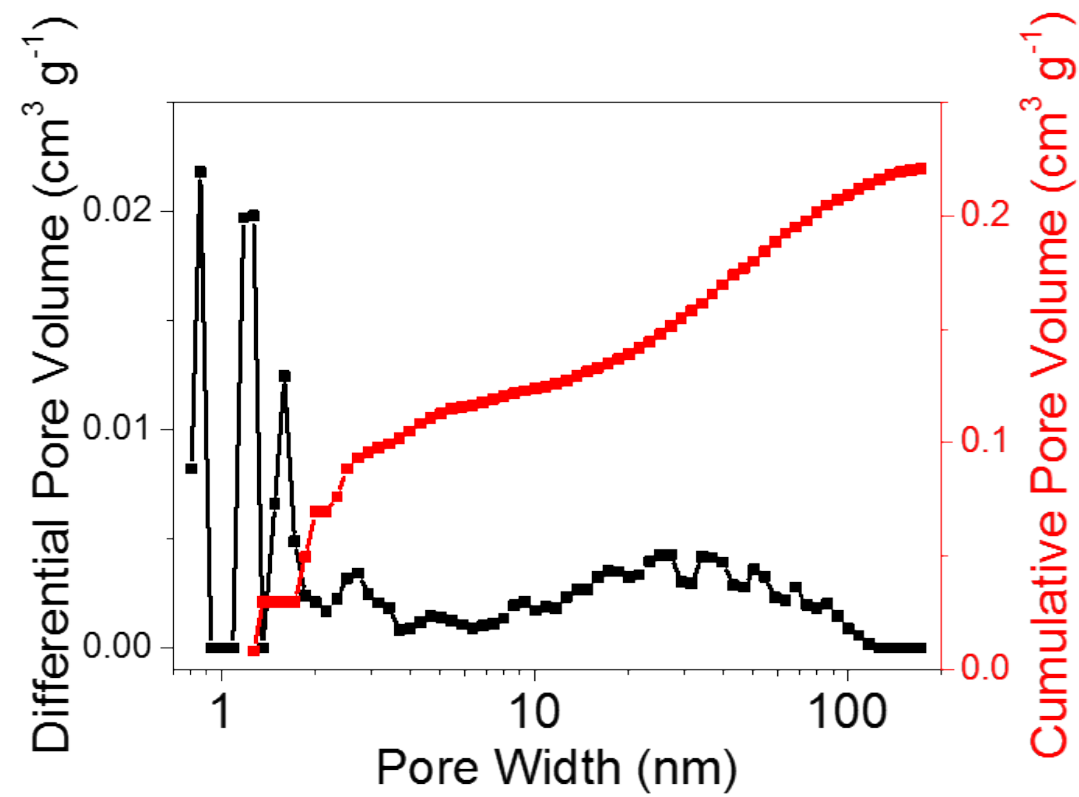

Figure S2. The pore size distribution and cumulative pore volume of DBTS-CMP1. 


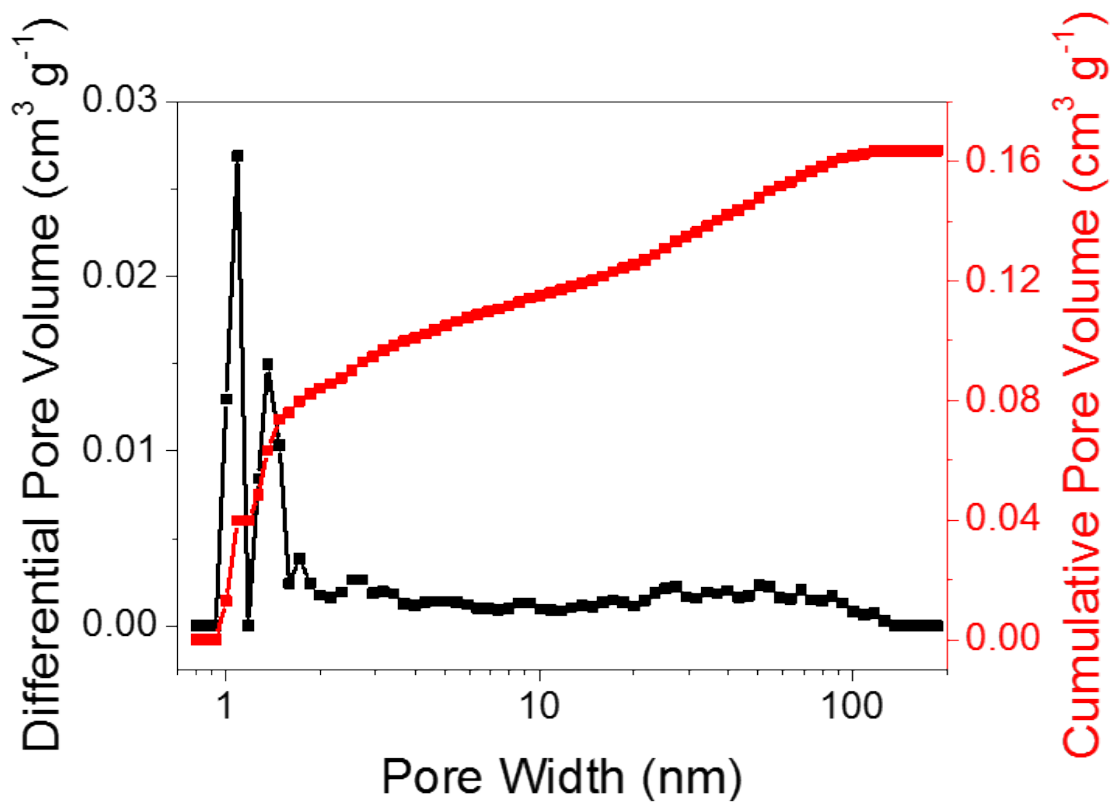

Figure S3. The pore size distribution and cumulative pore volume of DBBTS-CMP2.

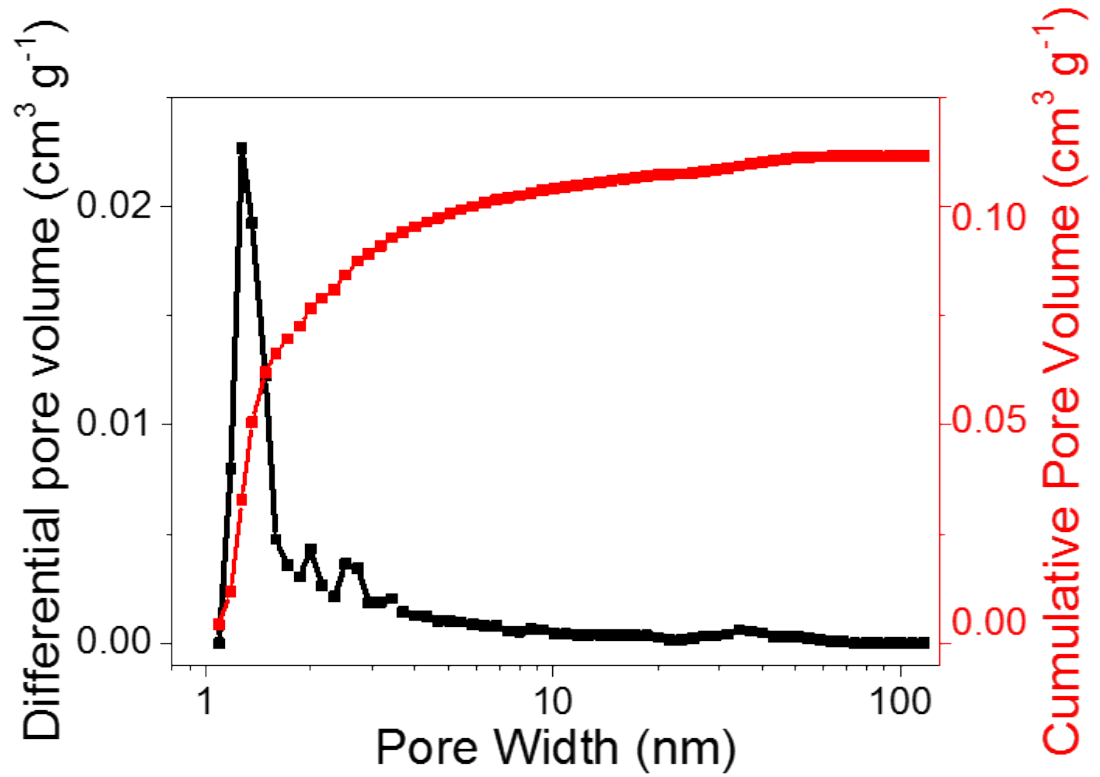

Figure S4. The pore size distribution and cumulative pore volume of BT-CMP3. 


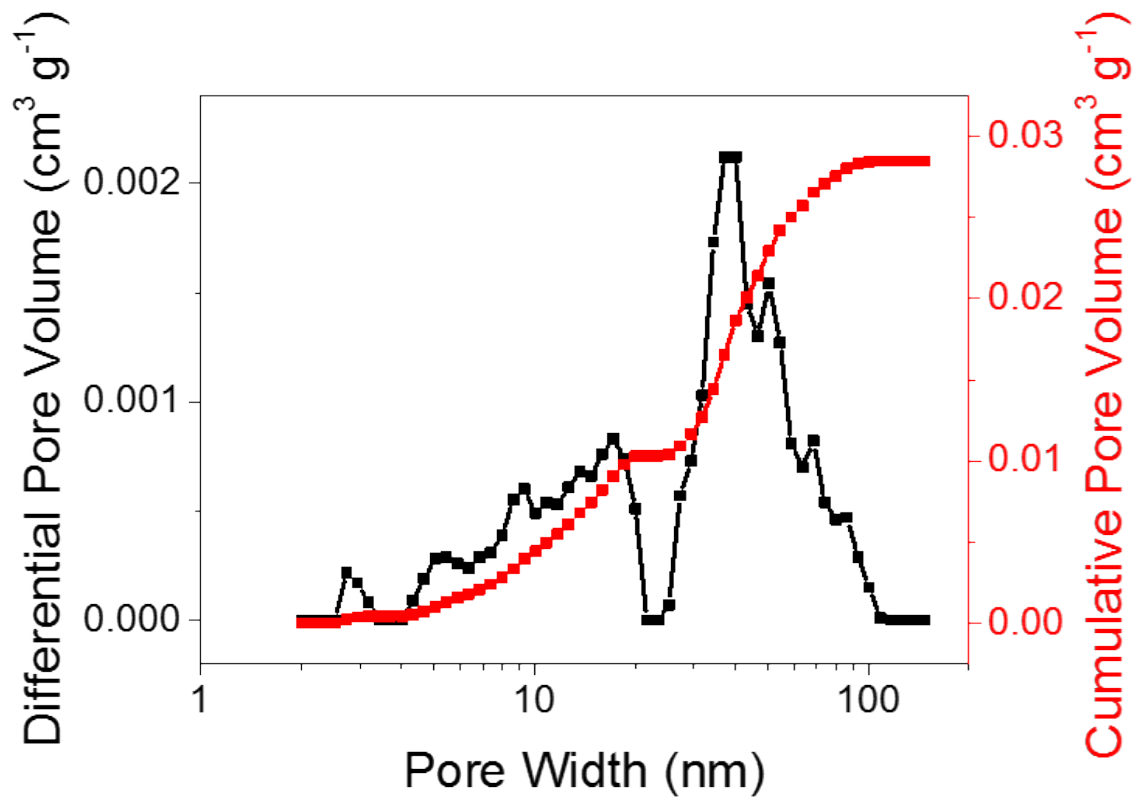

Figure S5. The pore size distribution and cumulative pore volume of DBTS-LP4.

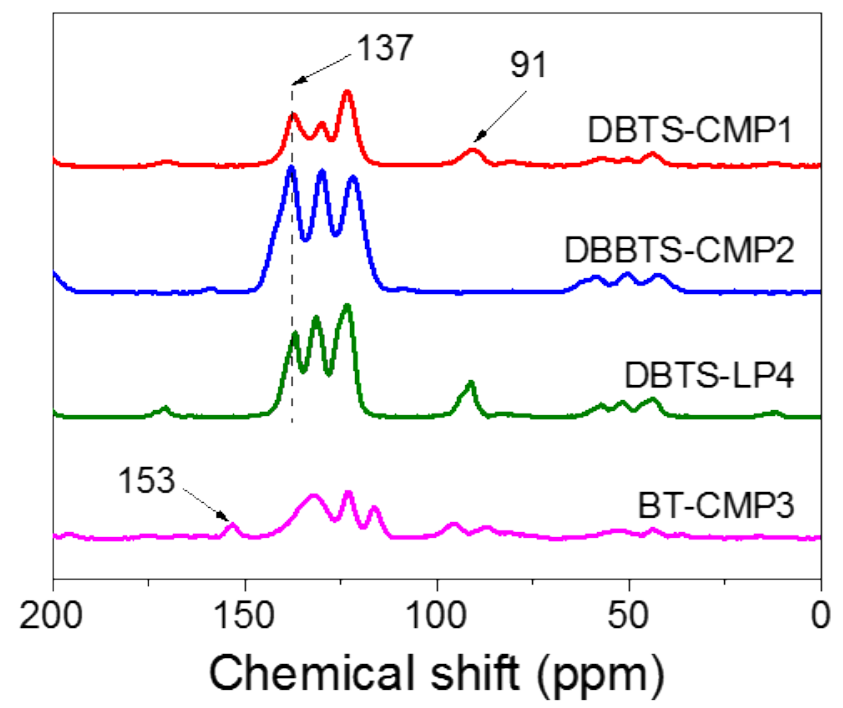

Figure S6. The solid-state ${ }^{13} \mathrm{C}$ CP-MAS NMR spectra of DBTS-CMP1, DBBTS-CMP2, BT-CMP3 and DBTS-LP4. 


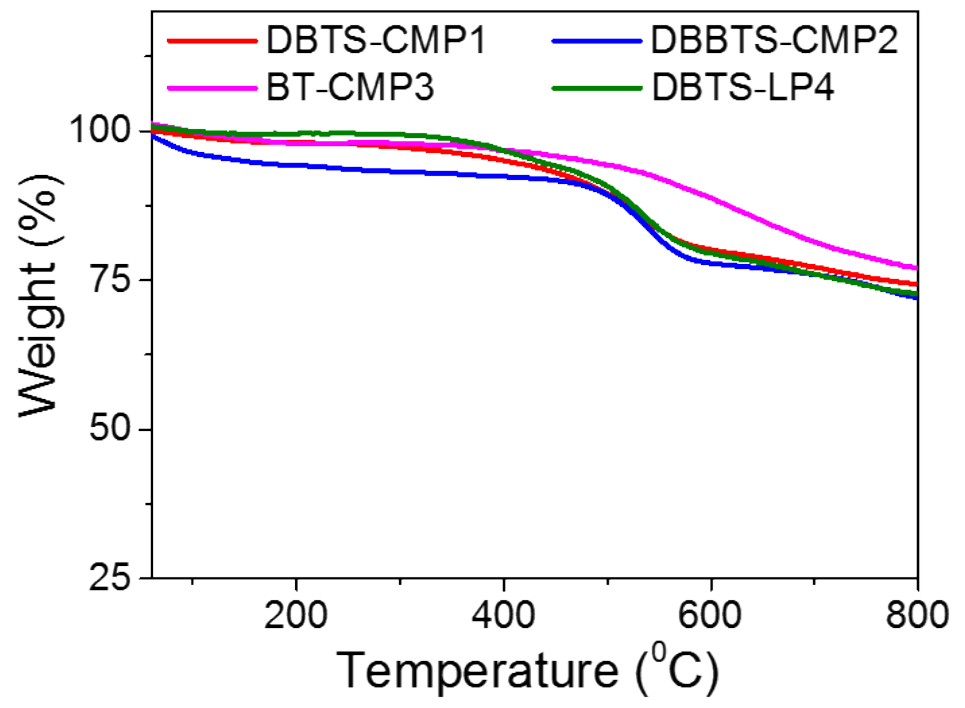

Figure S7. Thermogravimetric analysis curves of DBTS-CMP1, DBBTS-CMP2, BTCMP3 and DBTS-LP4.

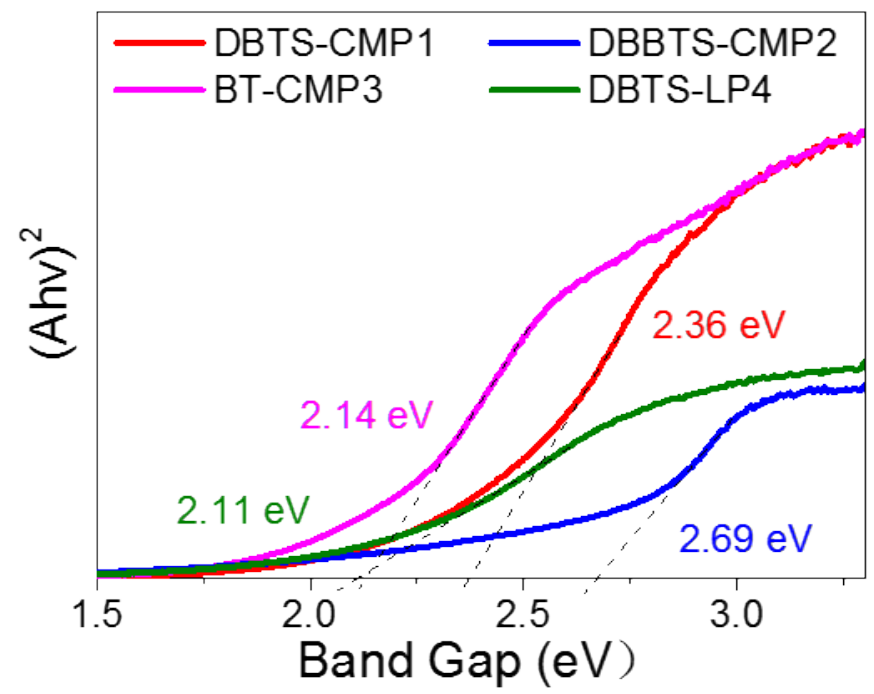

Figure S8. Kubelka-Munk plot of DBTS-CMP1, DBBTS-CMP2, BT-CMP3 and DBTSLP4. 


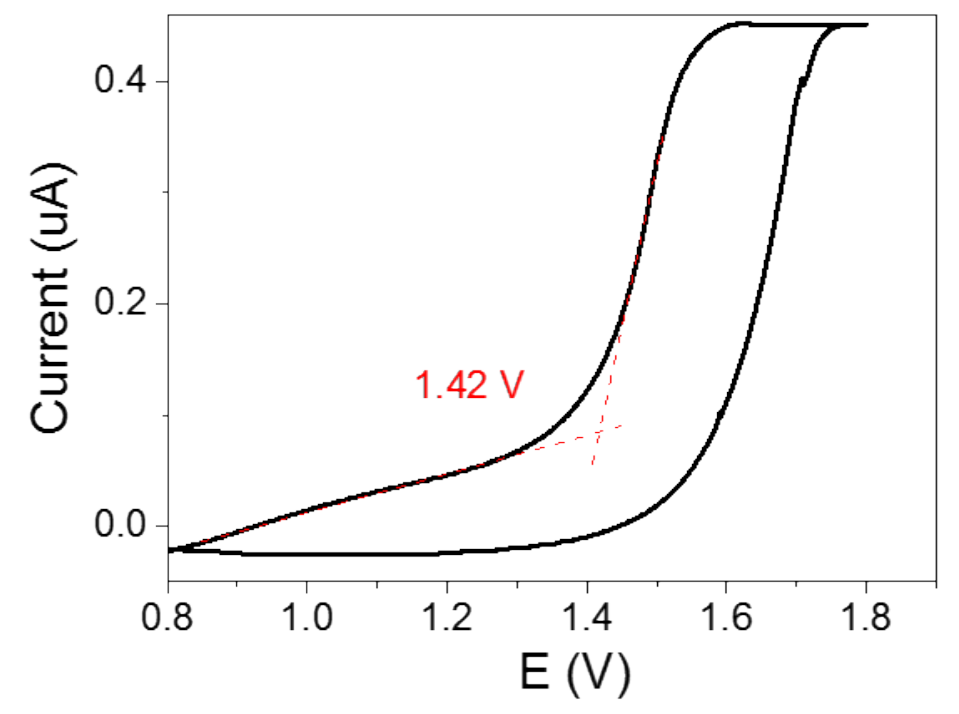

Figure S9. Cyclic voltammetry of DBTS-CMP1 in the oxidation cycle.

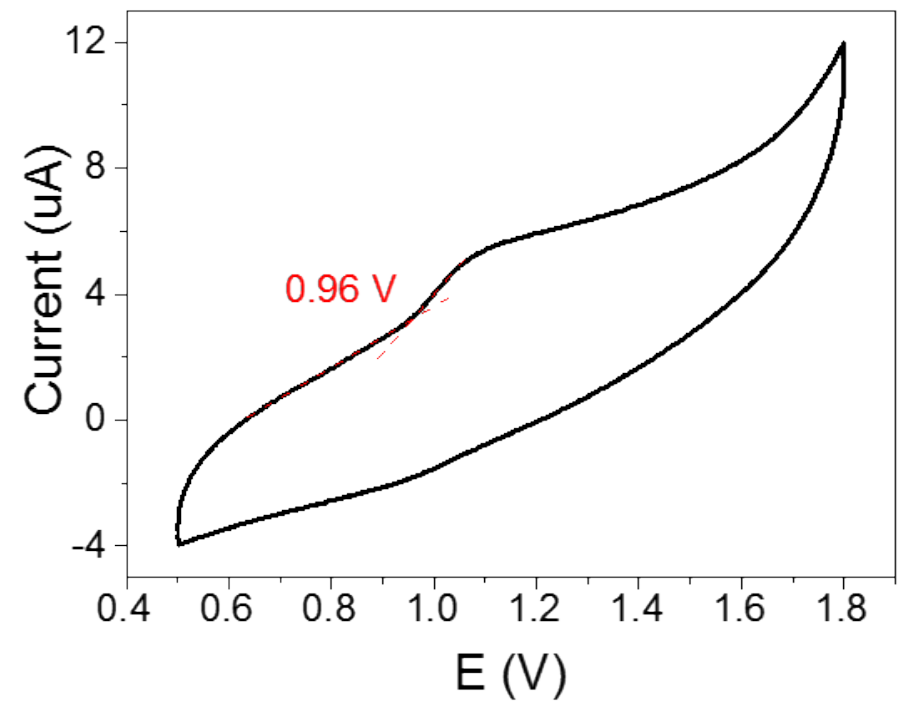

Figure S10. Cyclic voltammetry of DBBTS-CMP2 in the oxidation cycle. 


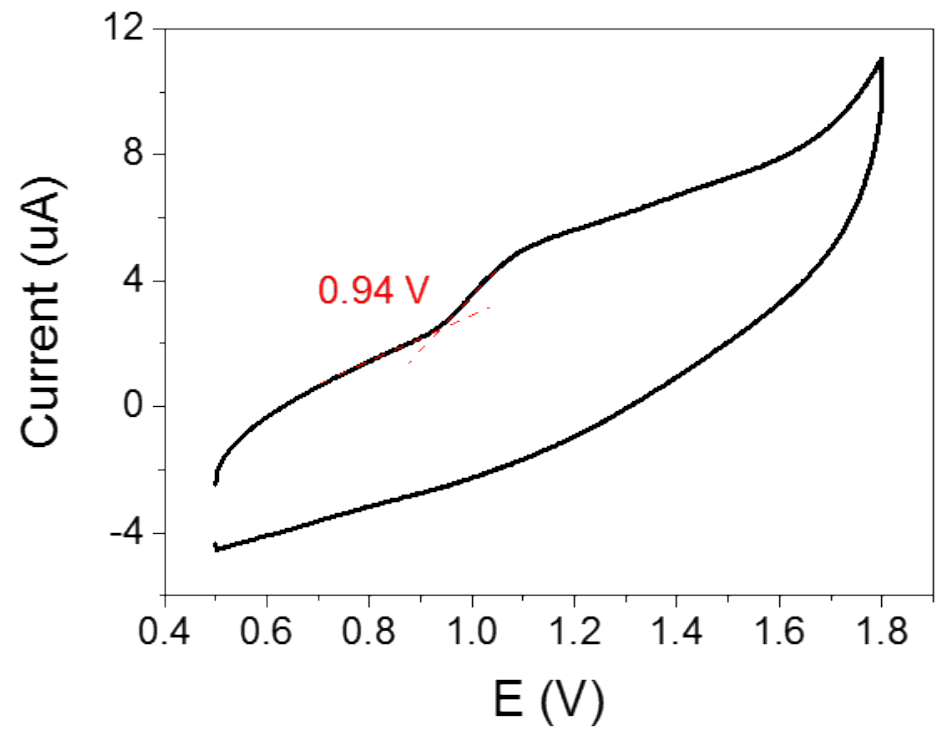

Figure S11. Cyclic voltammetry of BT-CMP3 in the oxidation cycle.

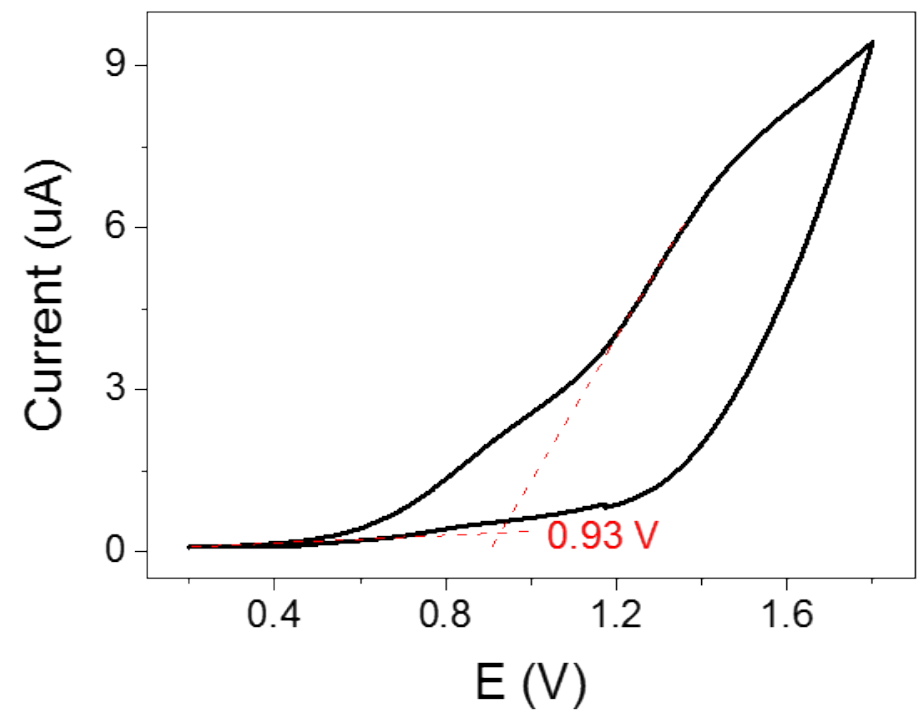

Figure S12. Cyclic voltammetry of DBTS-LP4 in the oxidation cycle. 


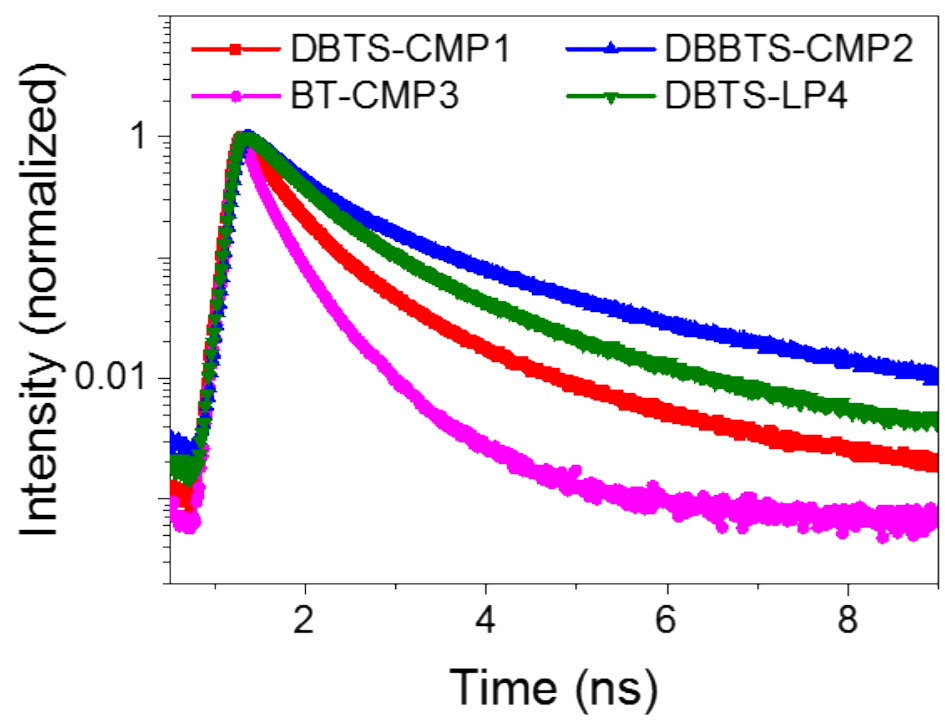

Figure S13. Time-resolved fluorescence decays for DBTS-CMP1, DBBTS-CMP2, BTCMP3 and DBTS-LP4.

(a)

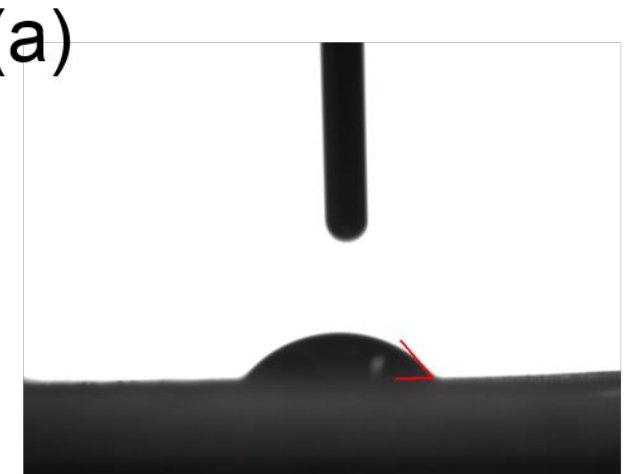

(b)

(c)

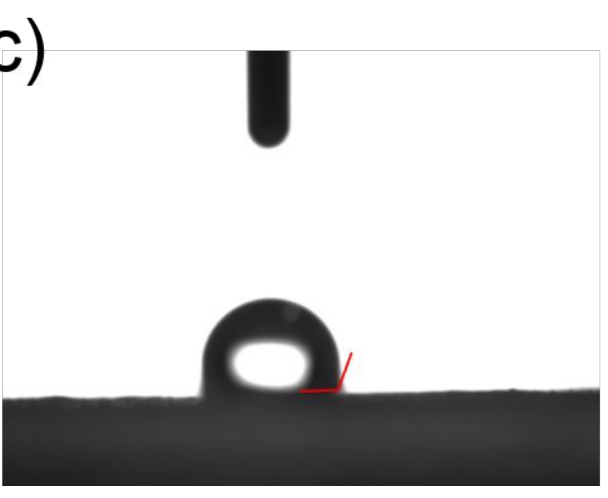

(d)
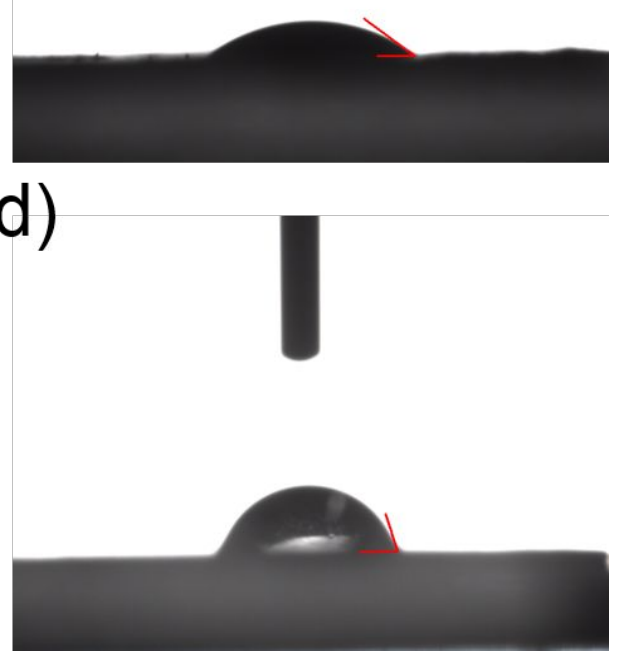

Figure S14. Optical images of a water droplet on the surface of DBTS-CMP1, DBBTSCMP2, BT-CMP3 and DBTS-LP4. 


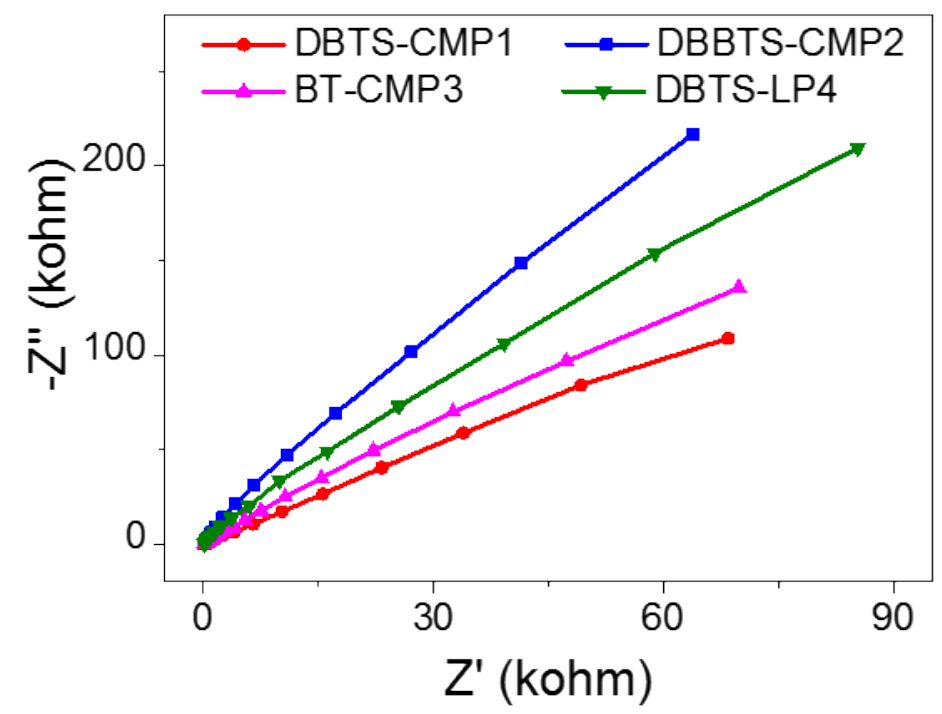

Figure S15. Comparison of electrochemical impedance spectroscopy of DBTS-CMP1, DBBTS-CMP2, BT-CMP3 and DBTS-LP4.

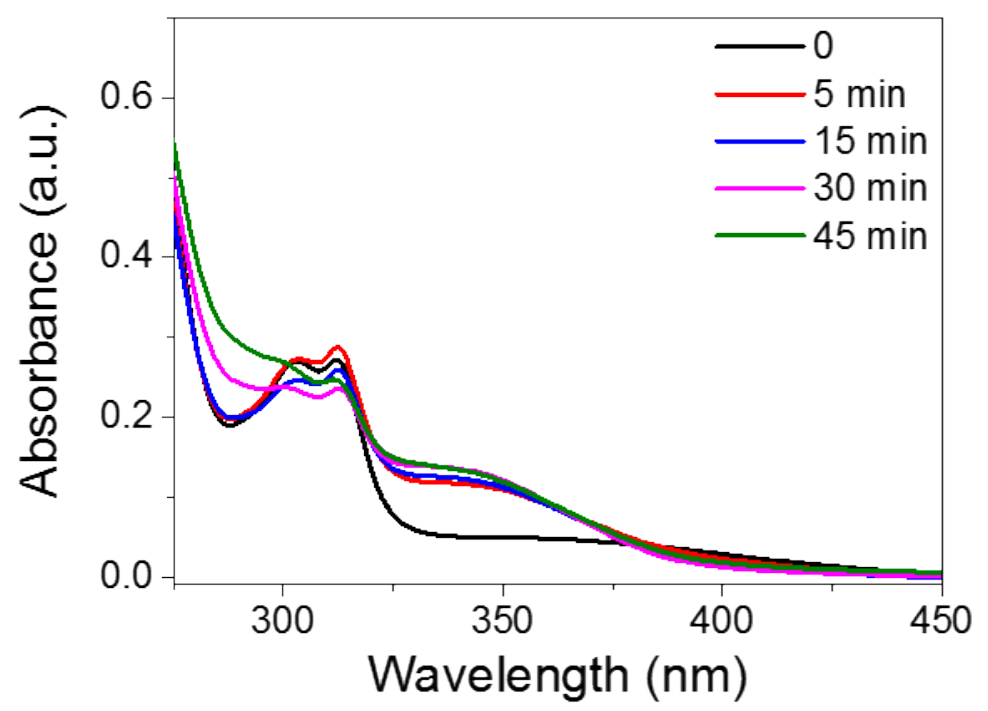

Figure S16. Spectral measurements of NADH concentration with DBBTS-CMP2 photocatalyst (DBBTS-CMP2 $1 \mathrm{mg} \mathrm{mL}^{-1}, \beta-\mathrm{NAD}^{+} 0.67 \mathrm{mM}$, TEOA $90 \mathrm{mM}$, $\left[\mathrm{Cp}{ }^{*} \mathrm{Rh}(\mathrm{bpy}) \mathrm{H}_{2} \mathrm{O}\right]^{2+} 0.2 \mathrm{mM}$, and phosphate buffer $0.01 \mathrm{M}, \mathrm{pH} 8$ ) 


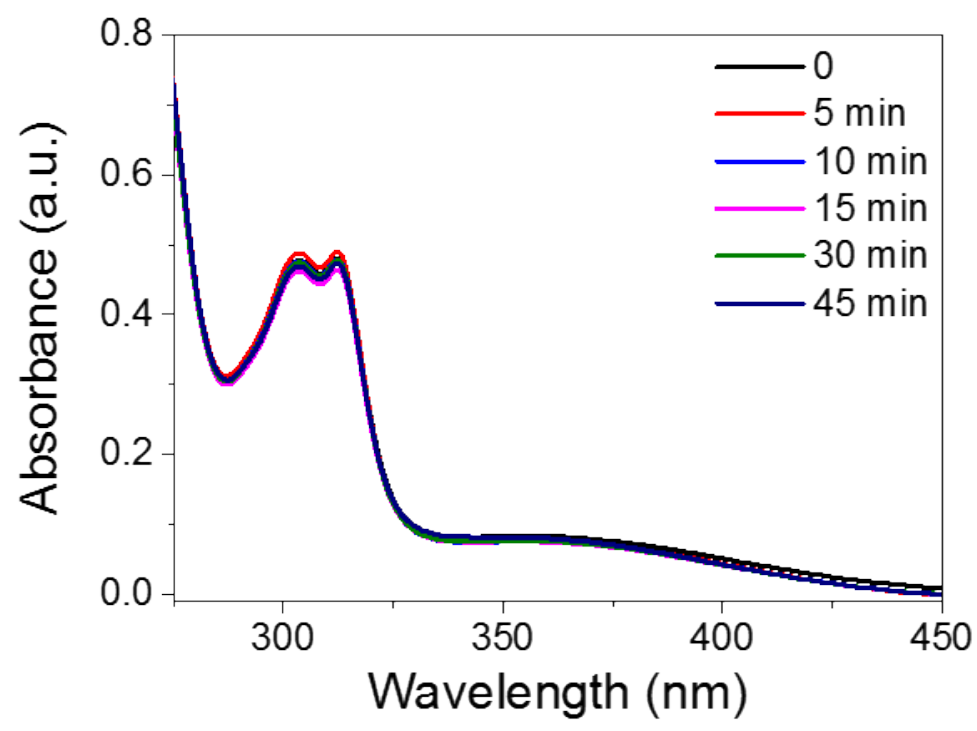

Figure S17. Spectral measurements of NADH concentration with BT-CMP3 photocatalyst (BT-CMP3 $1 \mathrm{mg} \mathrm{mL}^{-1}, \beta-\mathrm{NAD}^{+} 0.67 \mathrm{mM}$, TEOA $90 \mathrm{mM},\left[\mathrm{Cp}{ }^{*} \mathrm{Rh}(\mathrm{bpy}) \mathrm{H}_{2} \mathrm{O}^{2+}\right.$ $0.2 \mathrm{mM}$, and phosphate buffer $0.01 \mathrm{M}, \mathrm{pH} 8$ )

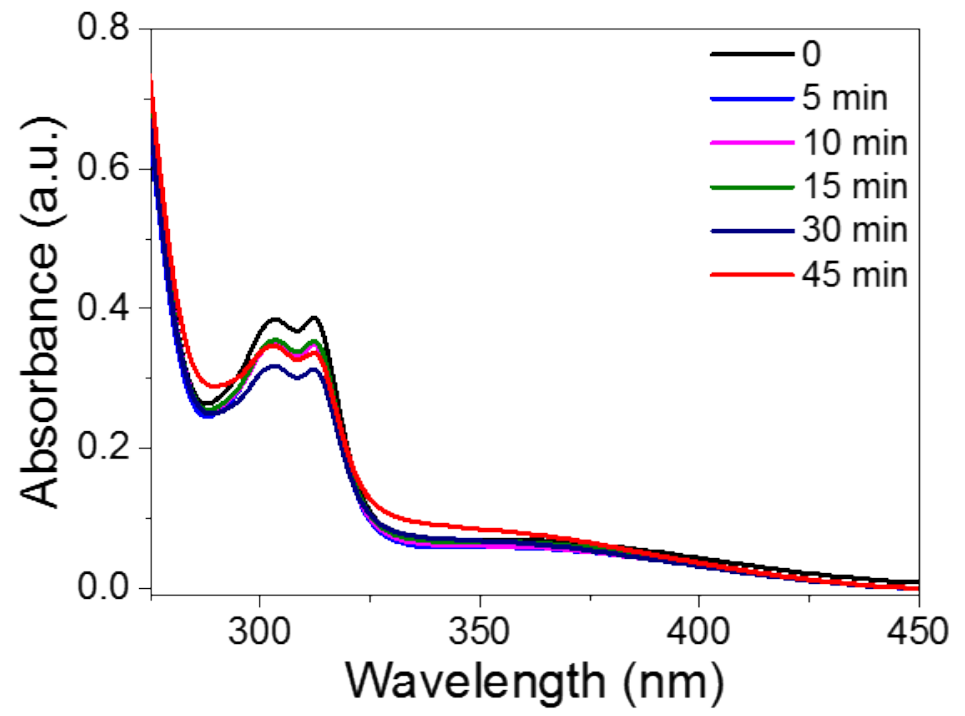

Figure S18. Spectral measurements of NADH concentration with DBTS-LP4 photocatalyst (DBTS-LP4 $1 \mathrm{mg} \mathrm{mL}^{-1}, \beta-\mathrm{NAD}^{+} 0.67 \mathrm{mM}$, TEOA $90 \mathrm{mM}$, $\left[\mathrm{Cp}{ }^{*} \mathrm{Rh}(\mathrm{bpy}) \mathrm{H}_{2} \mathrm{O}\right]^{2+} 0.2 \mathrm{mM}$, and phosphate buffer $0.01 \mathrm{M}, \mathrm{pH} 8$ ) 


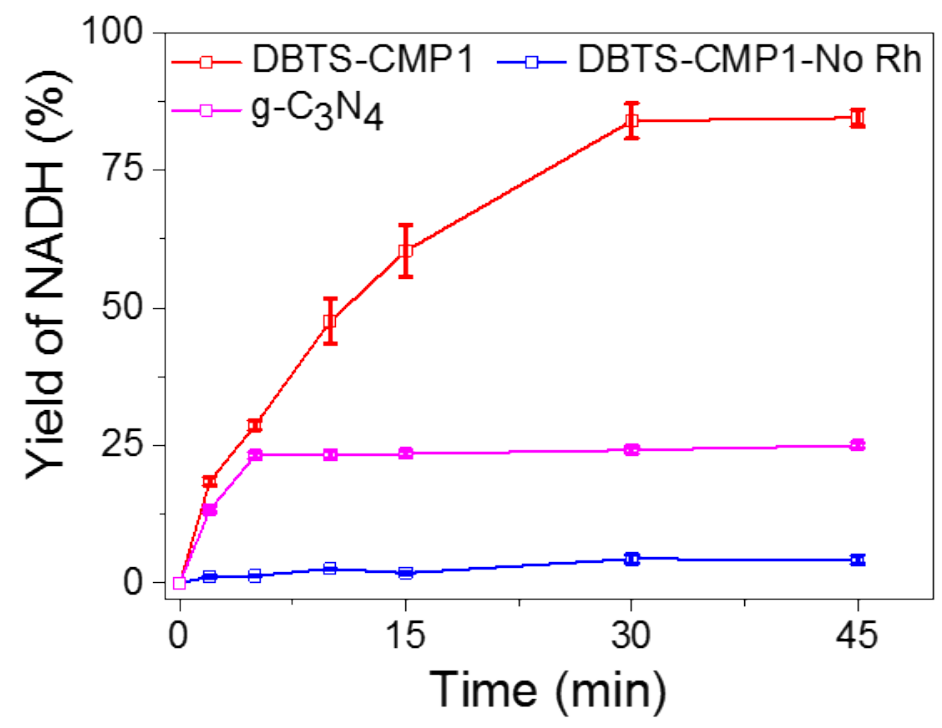

Figure S19. Time-resolved NADH regeneration yield in the presence (red) and absence (blue) of Rh complex using DBTS-CMP1 photocatalysts, and with g-C3N4 as photocatalyst (magenta). 
before light reaction

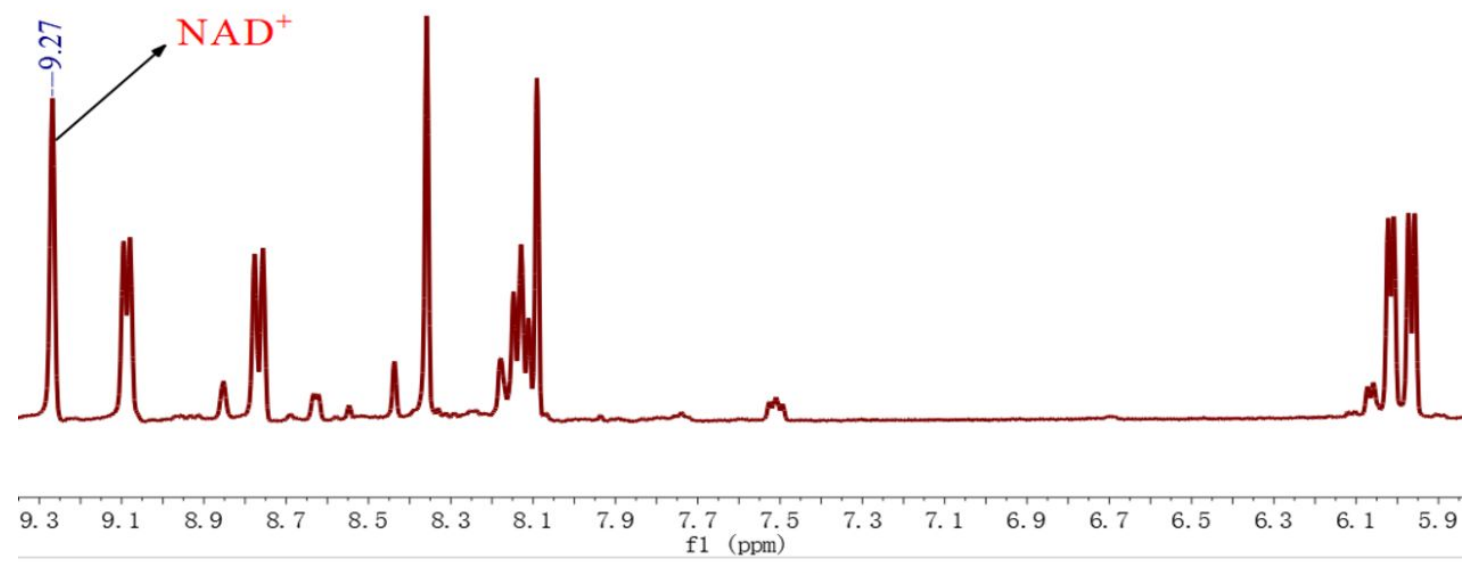

after 45 min light reaction

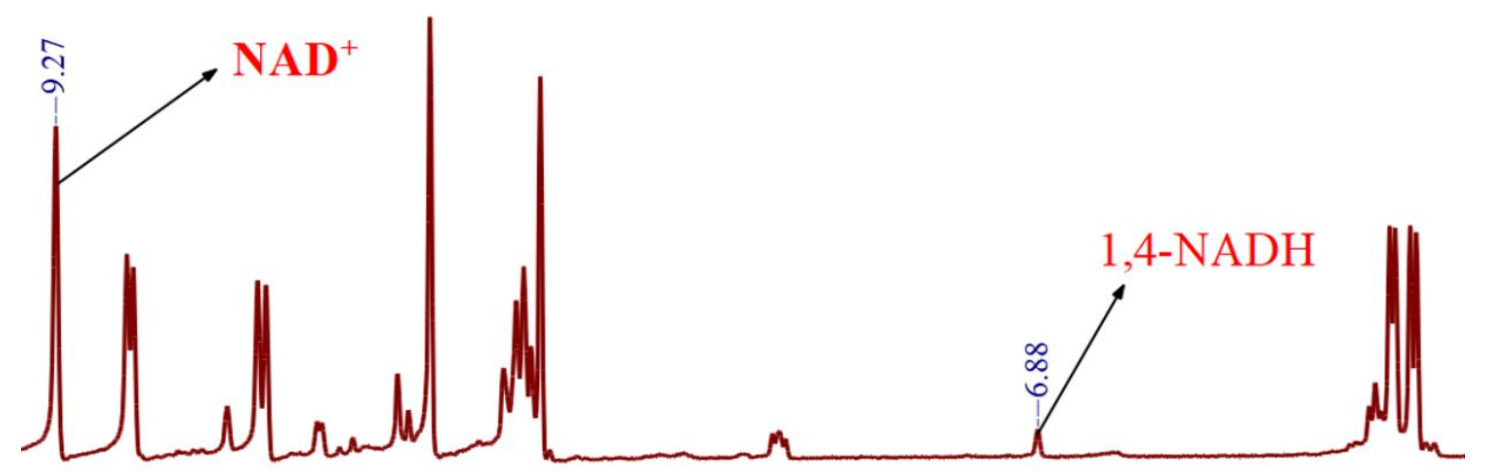

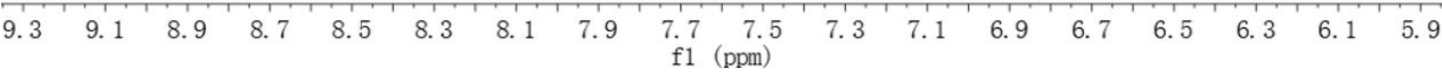

Figure S20. ${ }^{1} \mathrm{H}$ NMR spectra of before and after $45 \mathrm{~min}$ visible light irradiation with $\mathrm{Rh}$ complex in $\mathrm{D}_{2} \mathrm{O}$. Reaction condition: DBTS-CMP1 $1 \mathrm{mg} / \mathrm{ml}, \beta-\mathrm{NAD}^{+} 12 \mathrm{mM}$, TEOA 90 $\mathrm{mM}, \mathbf{M} 0.2 \mathrm{mM}$, phosphate buffer $0.01 \mathrm{M}, \mathrm{pH}=8$. 

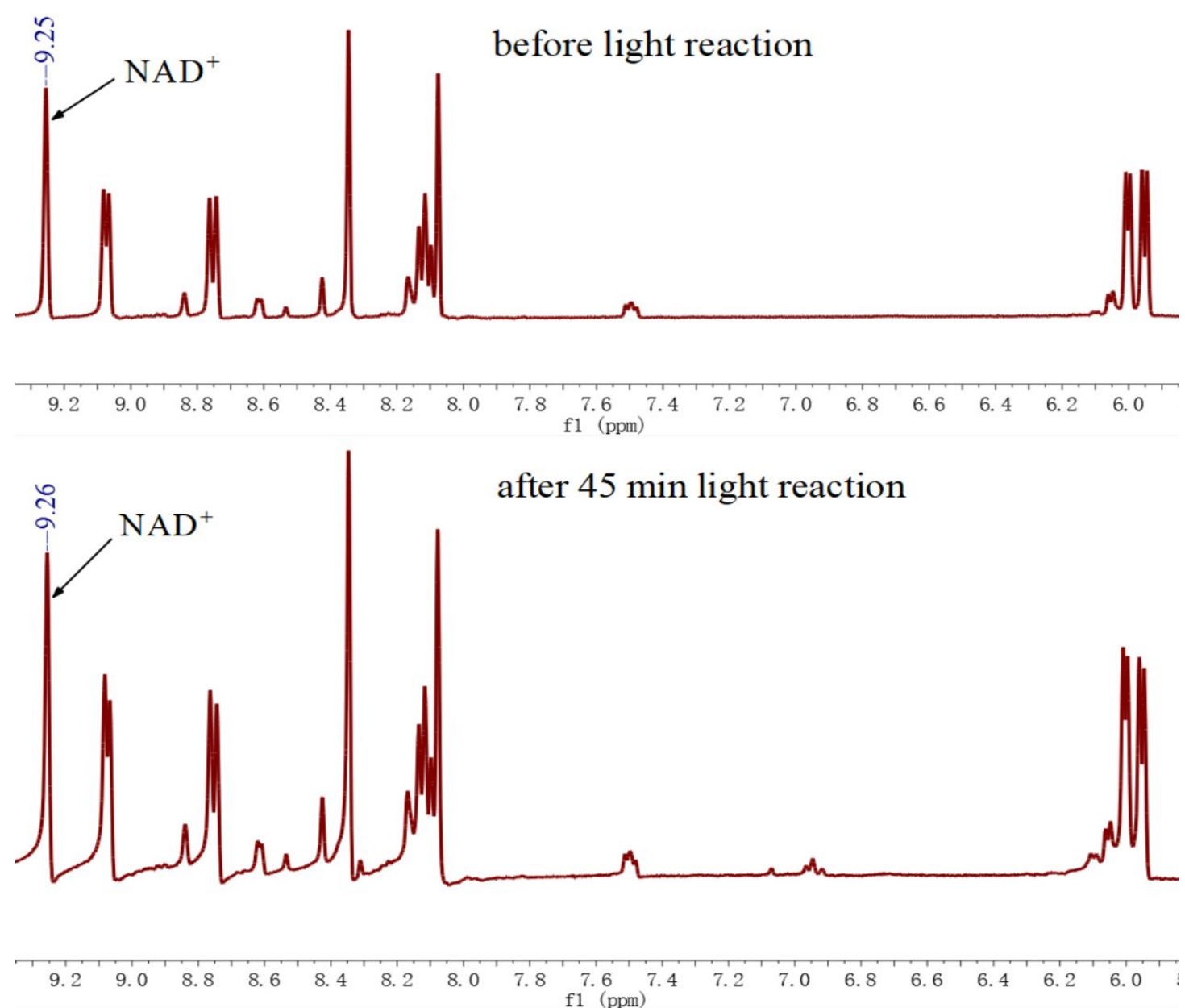

Figure S21. ${ }^{1} \mathrm{H}$ NMR spectra of before and after $45 \mathrm{~min}$ visible light irradiation without $\mathrm{Rh}$ complex in $\mathrm{D}_{2} \mathrm{O}$. Reaction condition: DBTS-CMP1 $1 \mathrm{mg} / \mathrm{ml}, \beta-\mathrm{NAD}^{+} 12 \mathrm{mM}$, TEOA 90 $\mathrm{mM}$, phosphate buffer $0.01 \mathrm{M}, \mathrm{pH}=8$. 


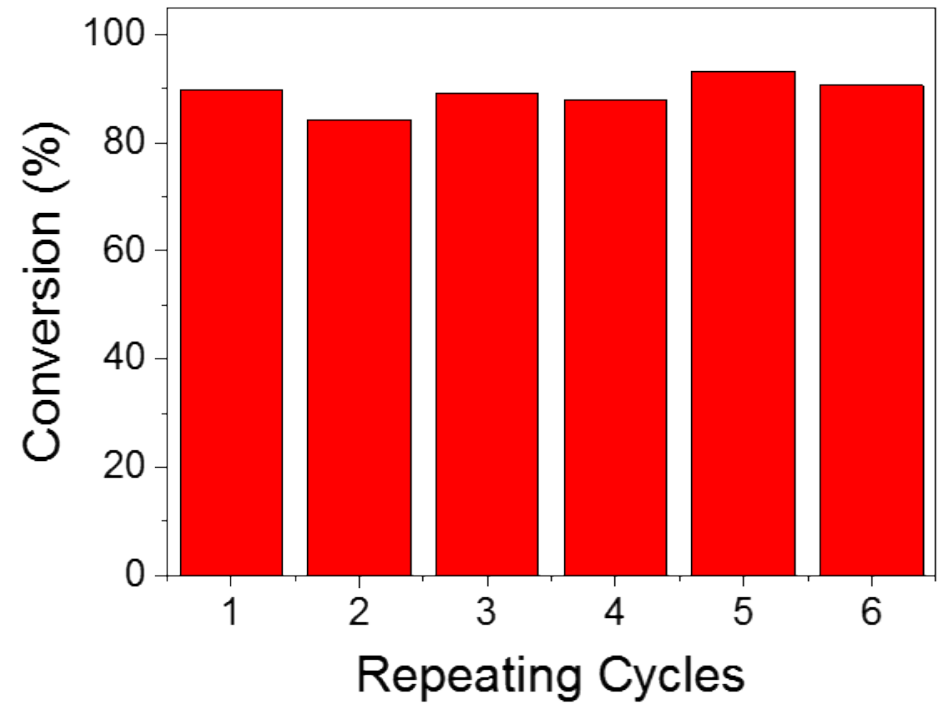

Figure S22. The repeating experiment of photocatalytic NADH regeneration using DBTSCMP1 photocatalyst.

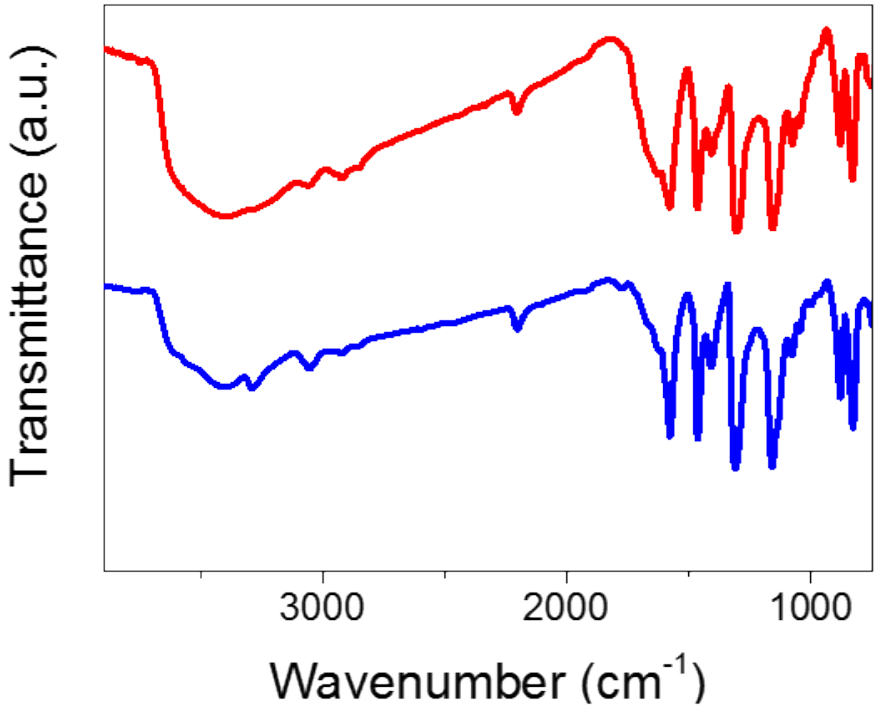

Figure S23. FTIR spectra of DBTS-CMP1 before (red) and after (blue) photocatalytic $\mathrm{NADH}$ regeneration reaction. 

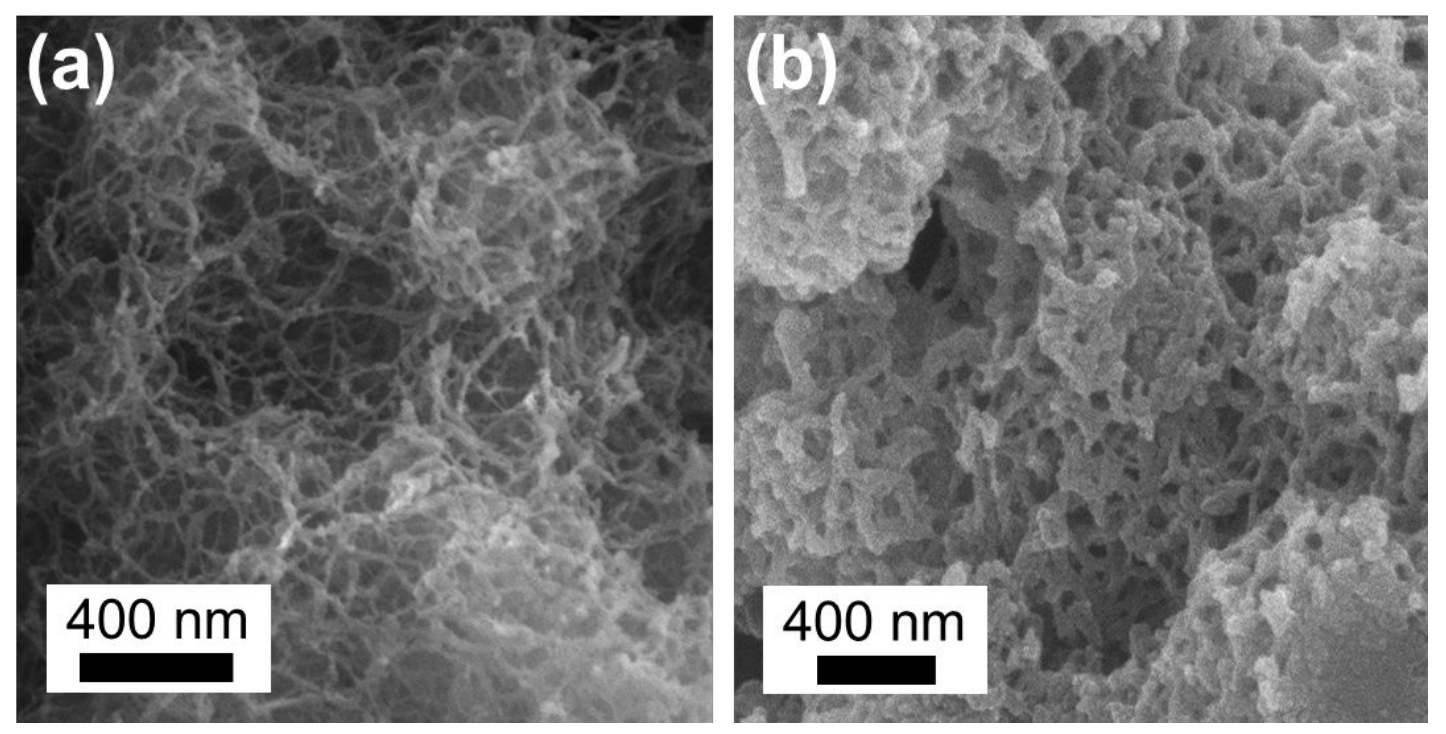

Figure S24. SEM images for DBTS-CMP1 before (a) and after (b) photocatalytic NADH regeneration reaction.

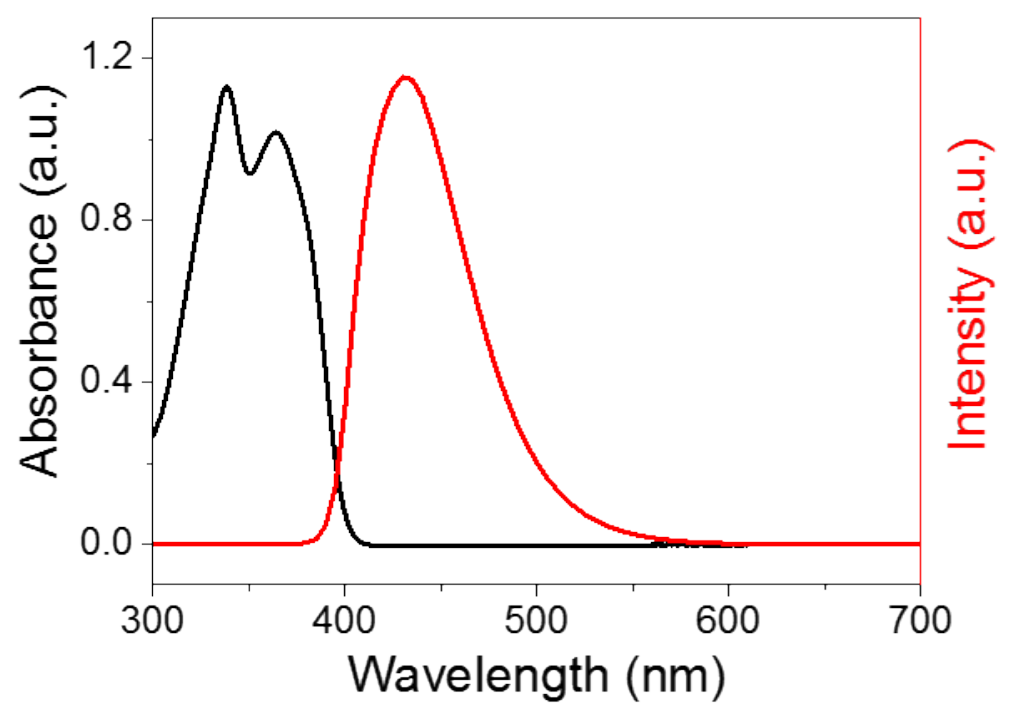

Figure S25. UV-Vis absorption (black) and fluorescence (red) spectra of DBTS-Ph2. 


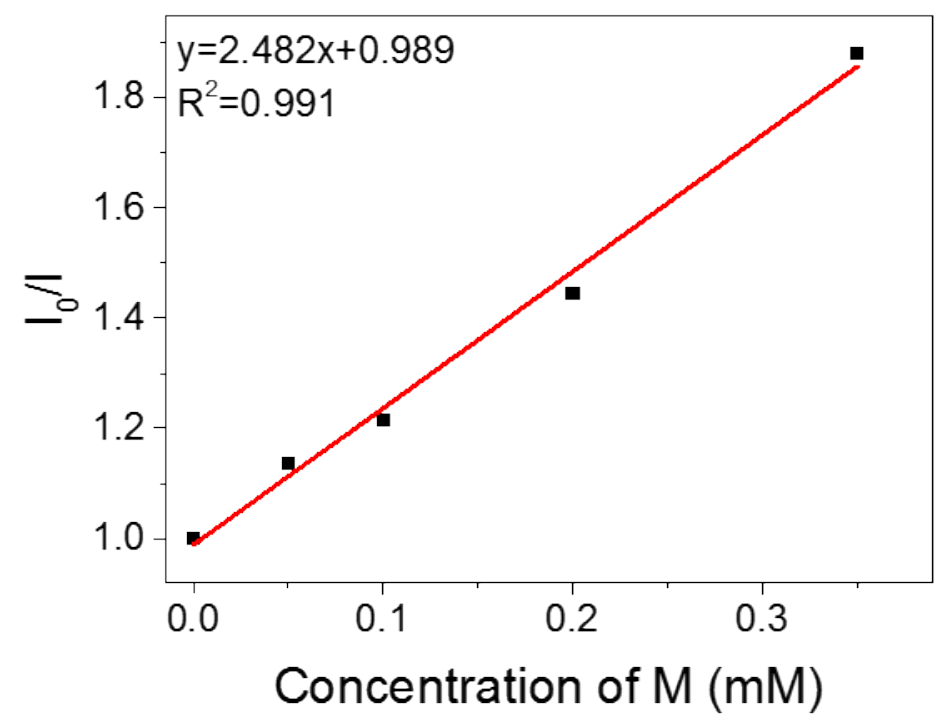

Figure S26. Stern-Volmer plots of DBTS-Ph2 in the presence of $\mathbf{M}$ mediator. $\mathrm{I}_{0}$ : emission intensity in the absence of $\mathbf{M}$ mediator and I: emission intensity in the presence of $\mathbf{M}$ mediator.

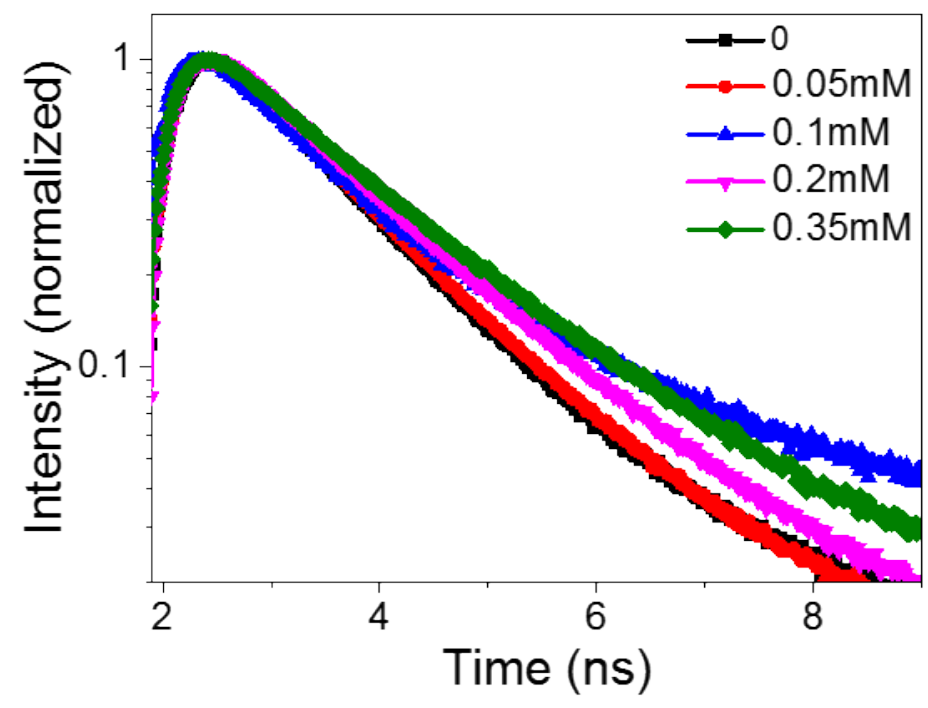

Figure S27. Time-resolved fluorescence decays for DBTS-Ph2 after additions of various concentrations of $\mathbf{M}$ mediator. 


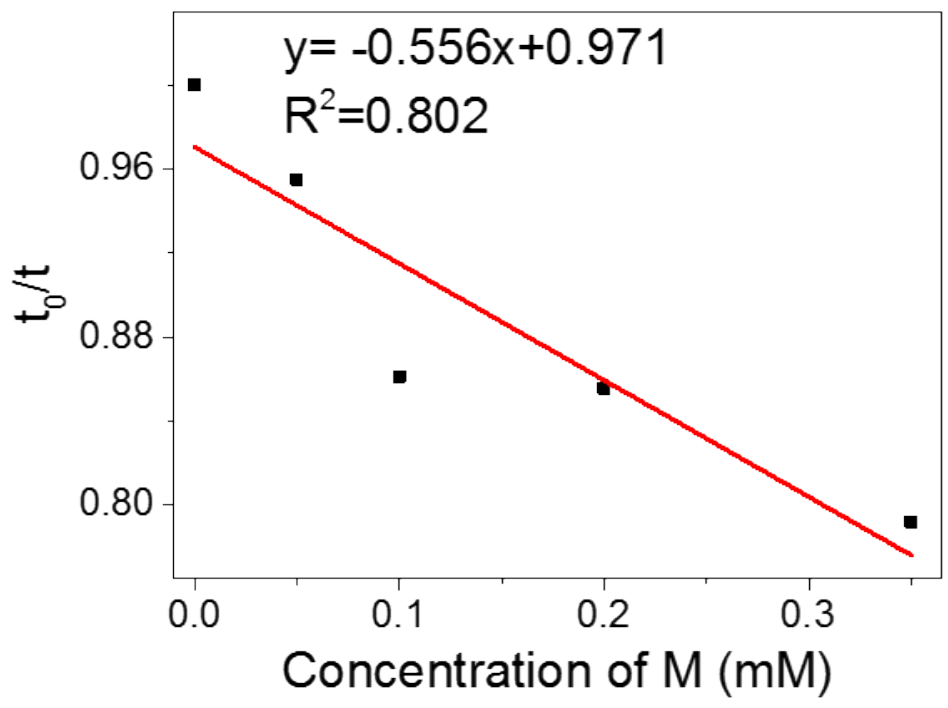

Figure S28. Time-resolved Stern-Volmer plots for DBTS-Ph2 in the presence of $\mathbf{M}$ mediator. $\mathrm{t}_{0}$ : fluorescence lifetime in the absence of $\mathbf{M}$ mediator and $\mathrm{t}$ : fluorescence lifetime in the presence of $\mathbf{M}$ mediator.

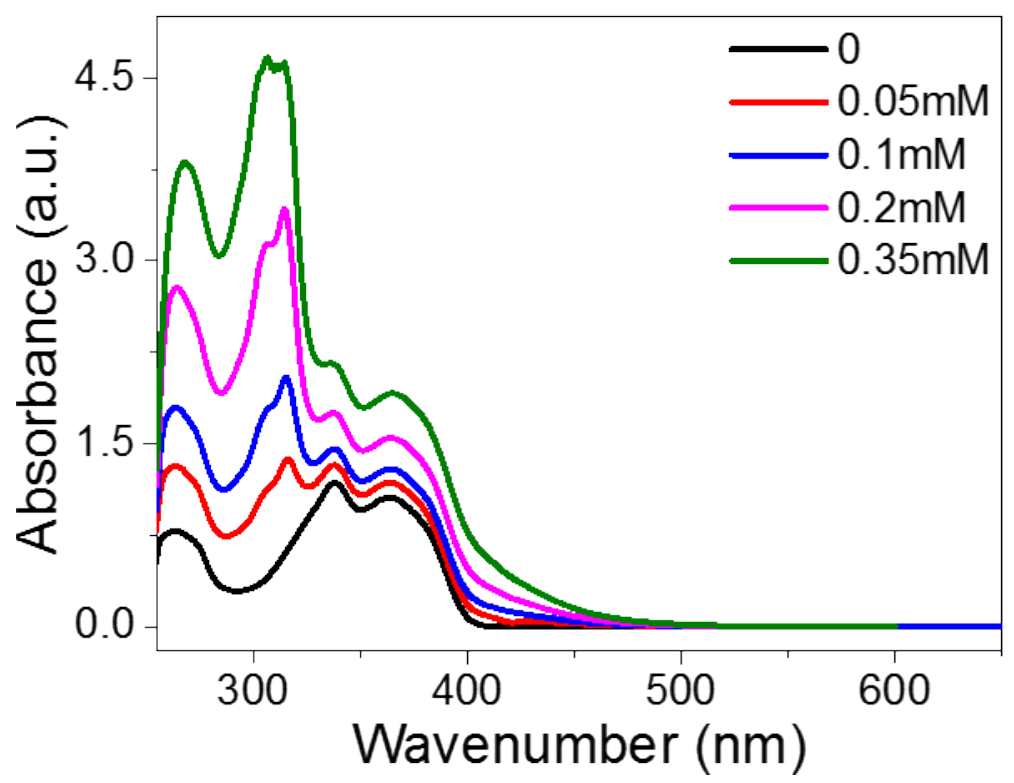

Figure S29. UV-Vis spectra of DBTS-Ph2 after adding various amounts of $\mathbf{M}$ mediator. Concentration of DBTS-Ph2 were $0.024 \mathrm{mM}$. 


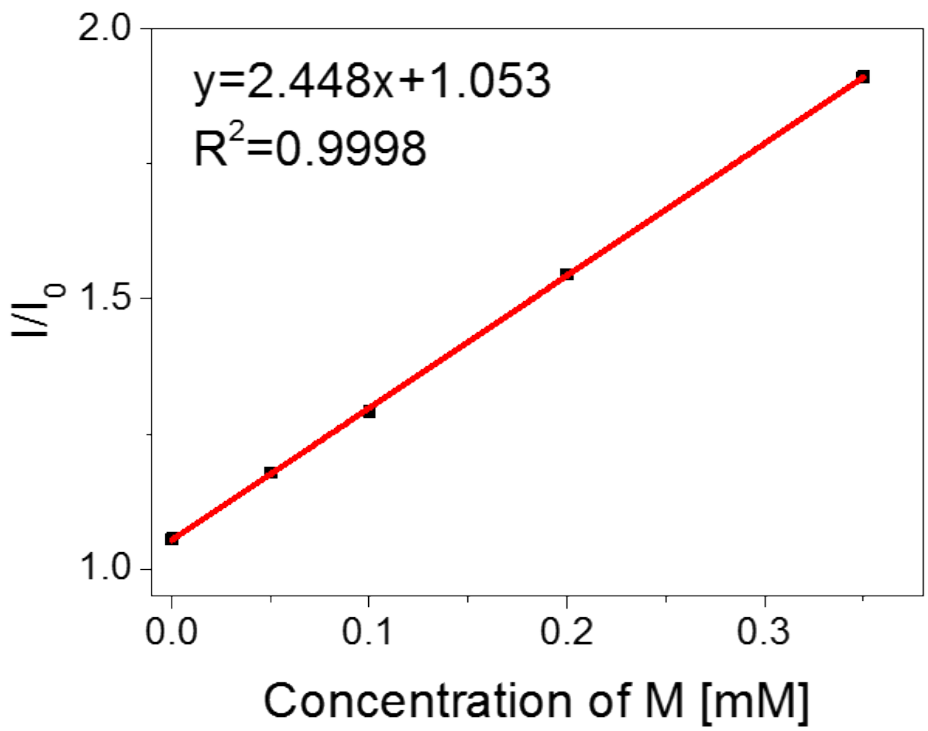

Figure S30. Absorption intensity change of DBTS-Ph2 in the presence of $\mathbf{M}$ mediator. $\mathrm{I}_{0}$ : absorption intensity at $365 \mathrm{~nm}$ in the absence of $\mathbf{M}$ and $\mathrm{I}$ : absorption intensity $365 \mathrm{~nm}$ in the presence of $\mathbf{M}$.

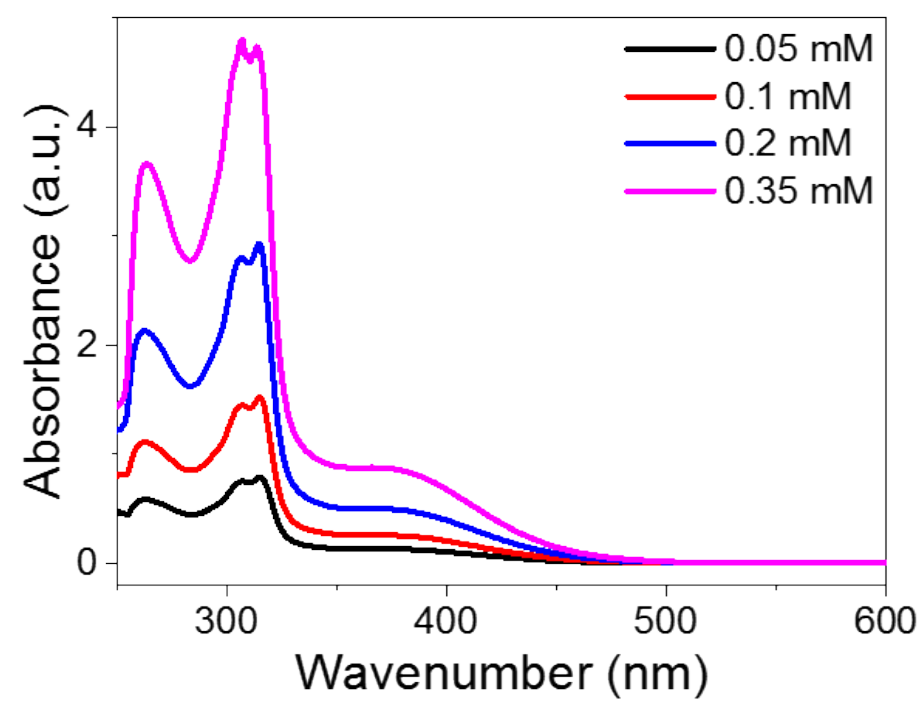

Figure S31. UV-Vis spectra of $\mathbf{M}$ mediator with various concentration from 0.05 to 0.35 $\mathrm{mM}$. 


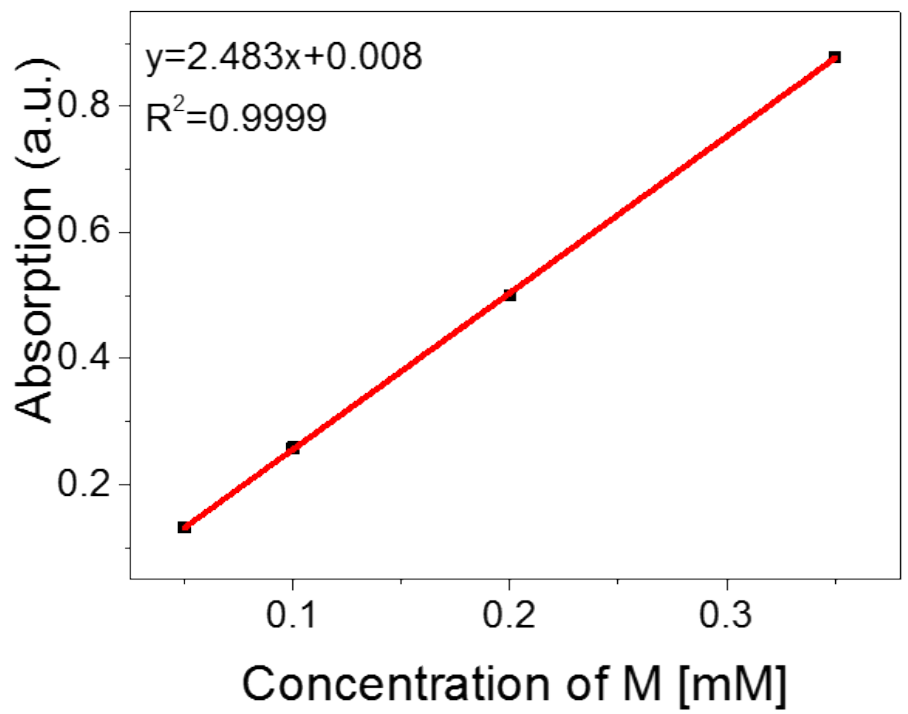

Figure S32. Absorption intensity change of $\mathbf{M}$ mediator at the position of $365 \mathrm{~nm}$ with different concentrations.

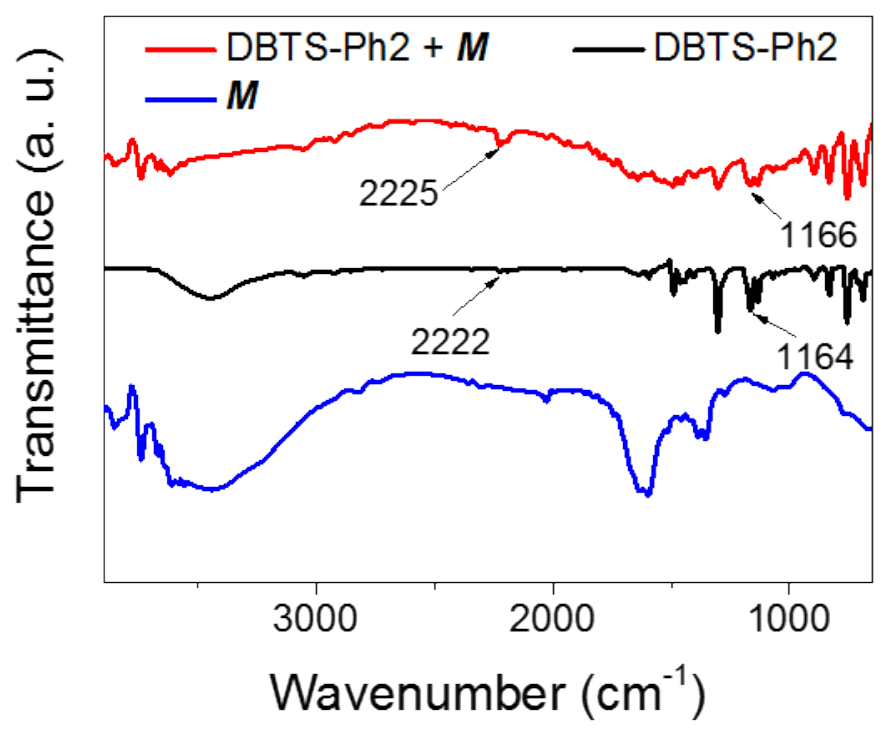

Figure S33. FTIR spectra of DBTS-Ph2 and $\mathbf{M}$ mixture (red), DBTS-Ph2 (black) and $\mathbf{M}$ mediator (blue). 


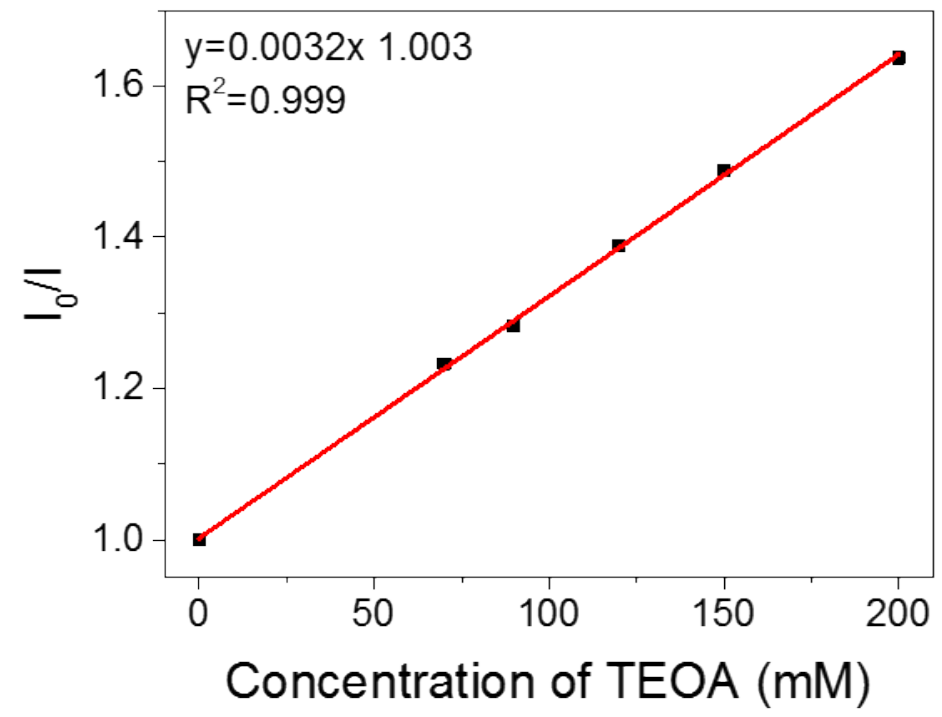

Figure S34. Stern-Volmer plots of DBTS-Ph2 in the presence of TEOA. I0: emission intensity in the absence of TEOA and I: emission intensity in the presence of TEOA.

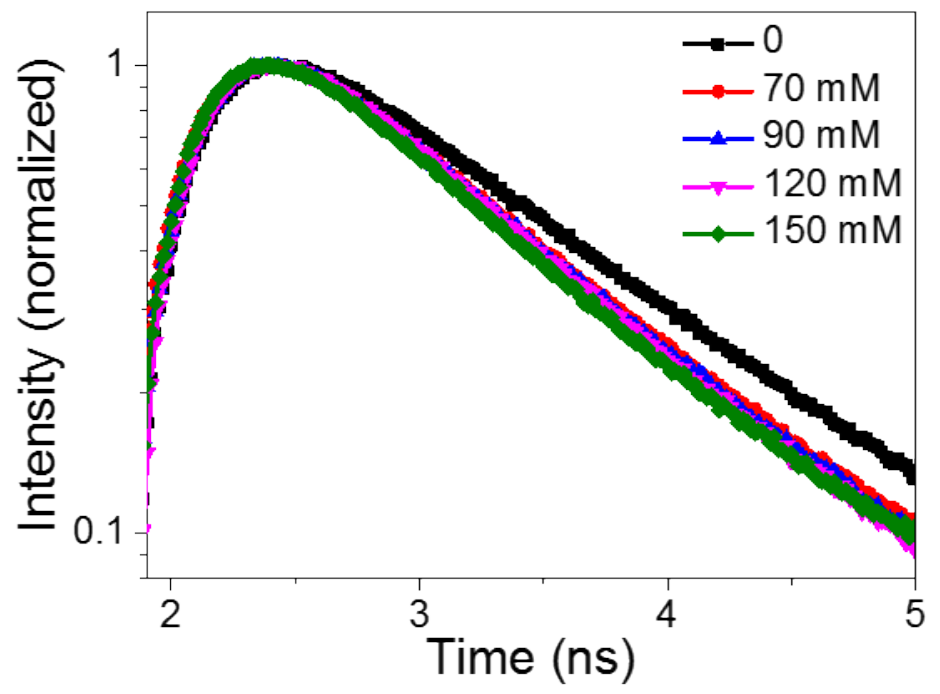

Figure S35. Time-resolved fluorescence decays for DBTS-Ph2 after additions of various concentrations of TEOA. 


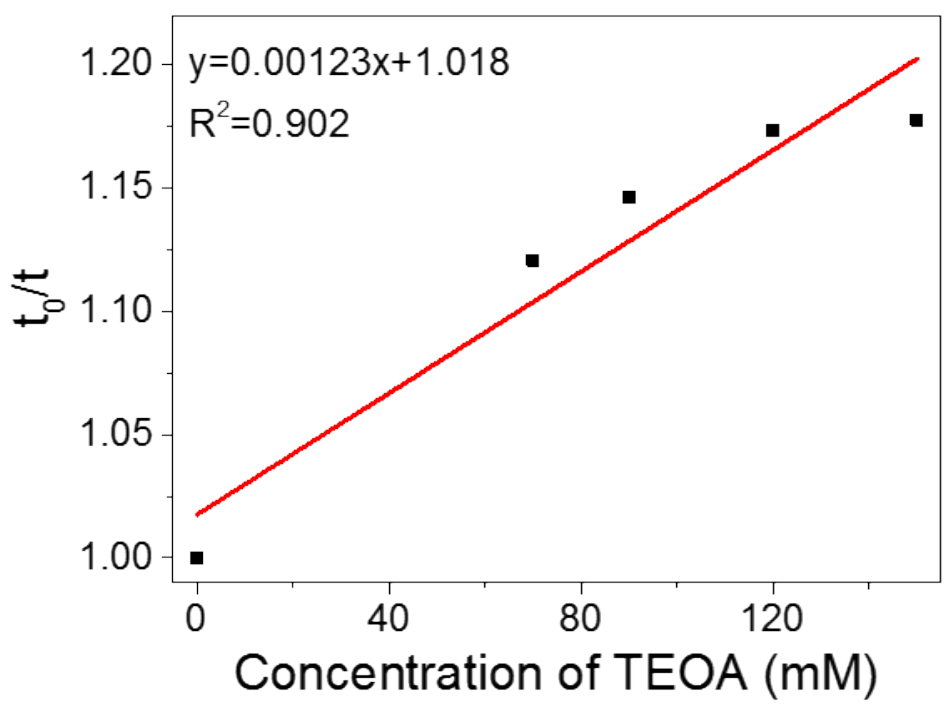

Figure S36. Time-resolved Stern-Volmer plots for DBTS-Ph2 in the presence of TEOA. $t_{0}$ : fluorescence lifetime in the absence of TEOA and $t$ : fluorescence lifetime in the presence of TEOA.

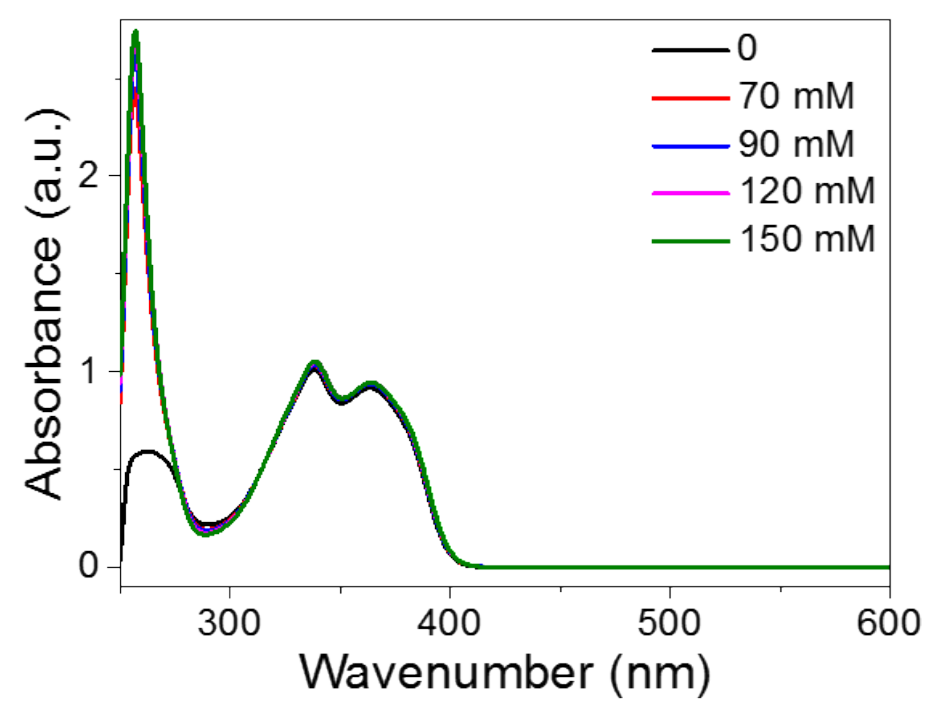

Figure S37. UV-Vis spectra of DBTS-Ph2 after adding various amounts of TEOA. Concentration of DBTS-Ph2 were $0.024 \mathrm{mM}$. 


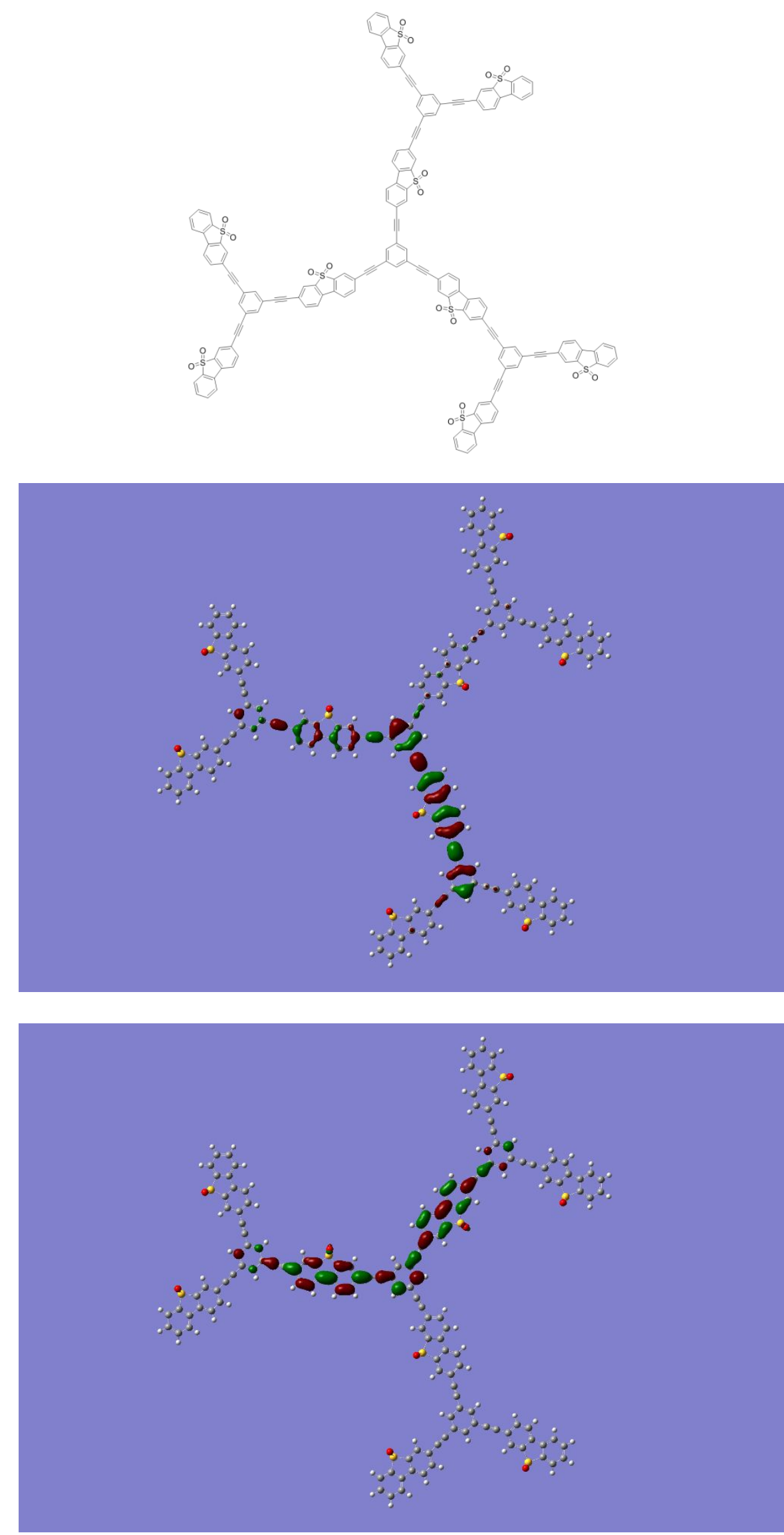

Figure S38. Chemical structure and molecular orbital (HOMO in the upper and LUMO in 
the lower part) diagrams of fragmental structures of DBTS-CMP1.
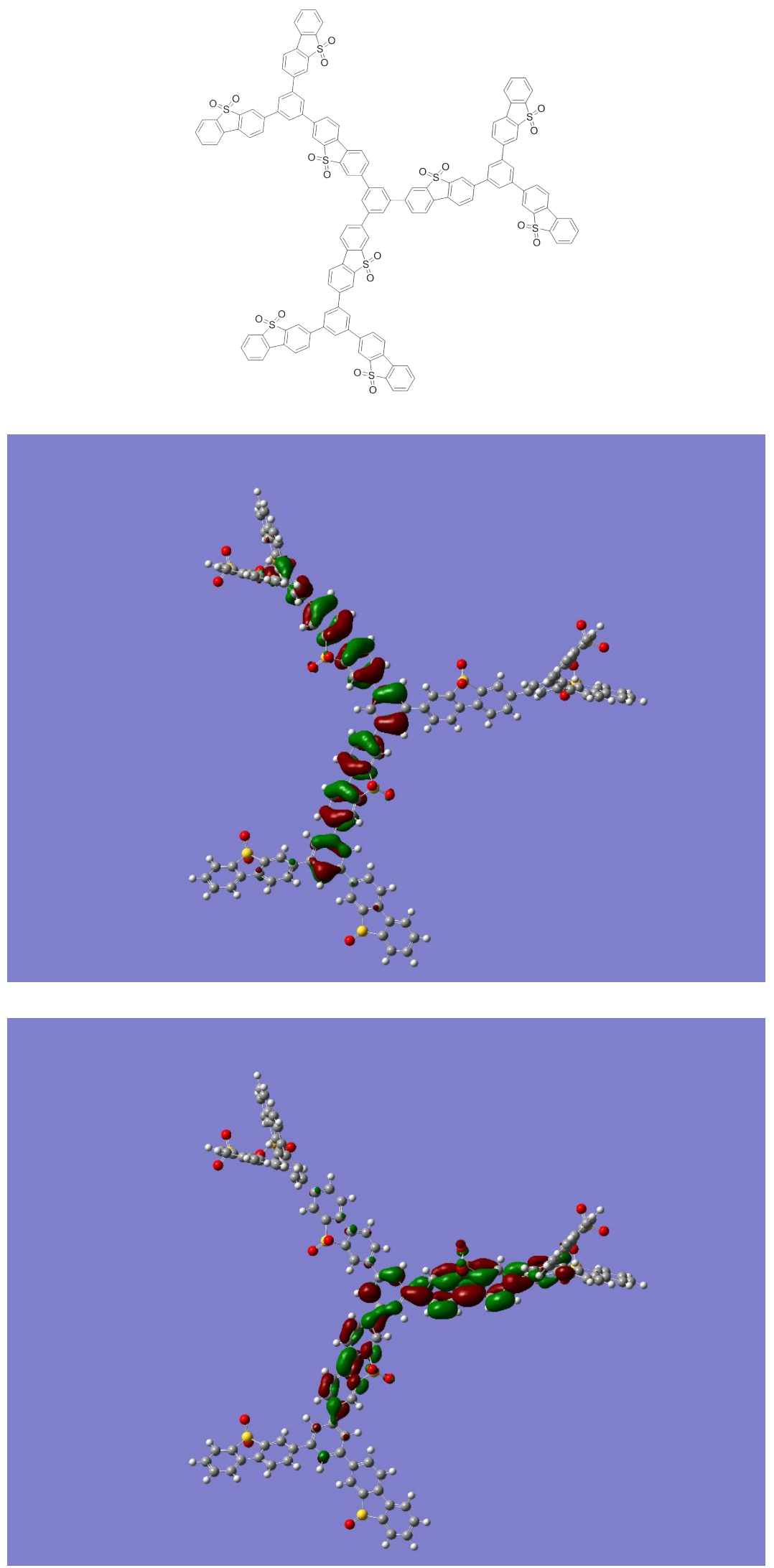

Figure S39. Chemical structure and molecular orbital (HOMO in the upper and LUMO in the lower part) diagrams of fragmental structures of DBBTS-CMP2. 

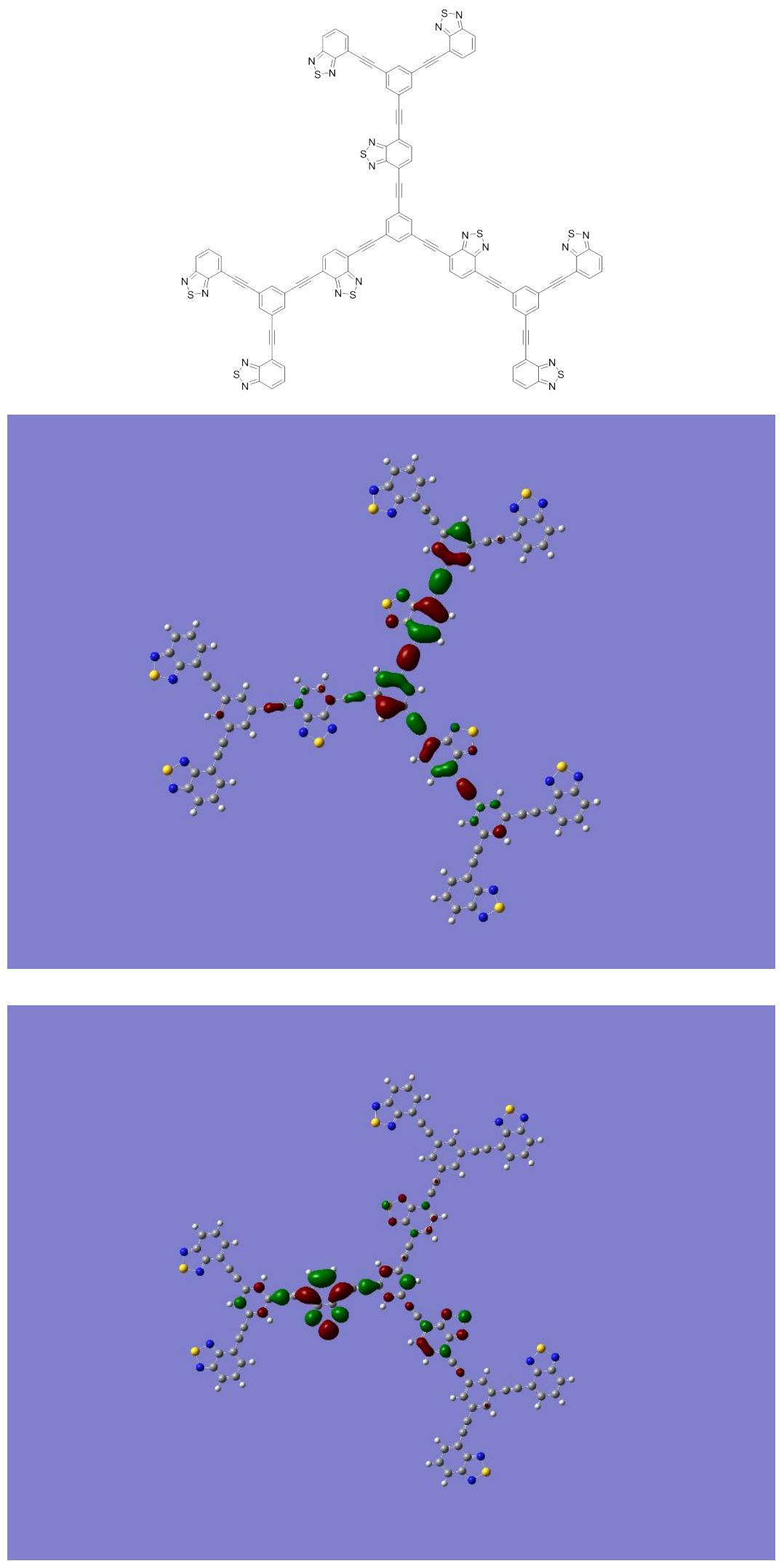

Figure S40. Chemical structure and molecular orbital (HOMO in the upper and LUMO in the lower part) diagrams of fragmental structures of BT-CMP-3. 

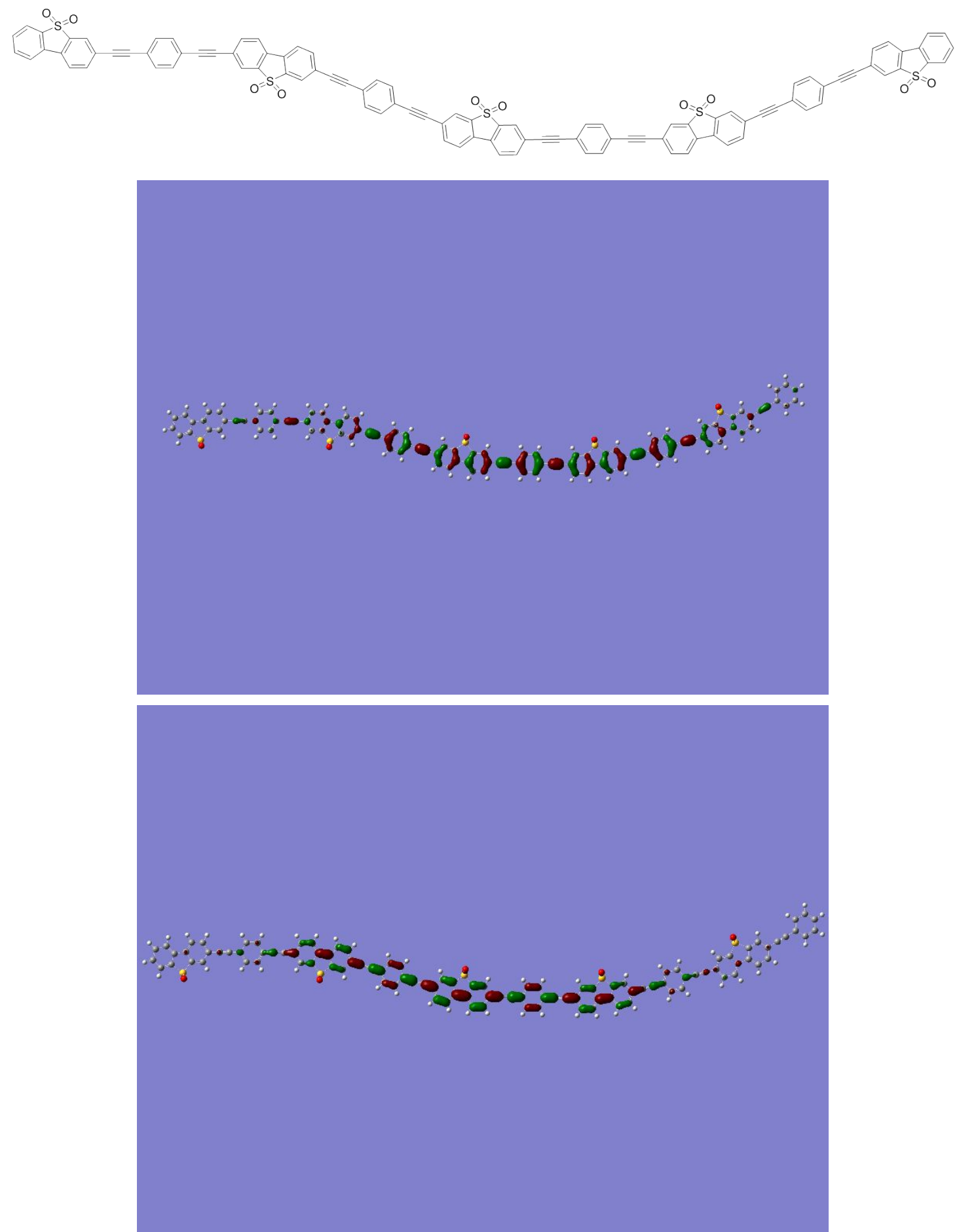

Figure S41. Chemical structure and molecular orbital (HOMO in the upper and LUMO in the lower part) diagrams of fragmental structures of DBTS-LP4. 
NMR spectra
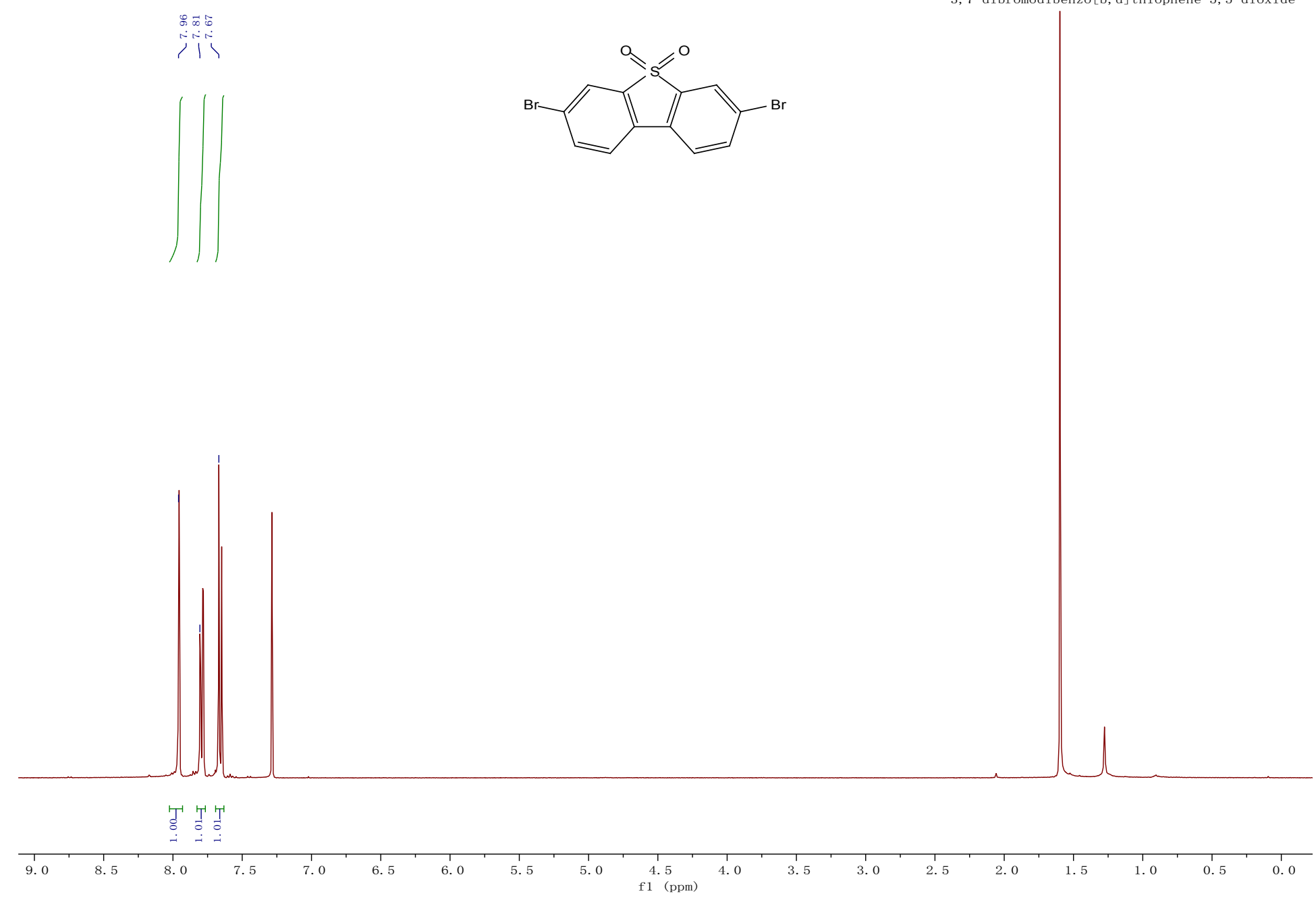


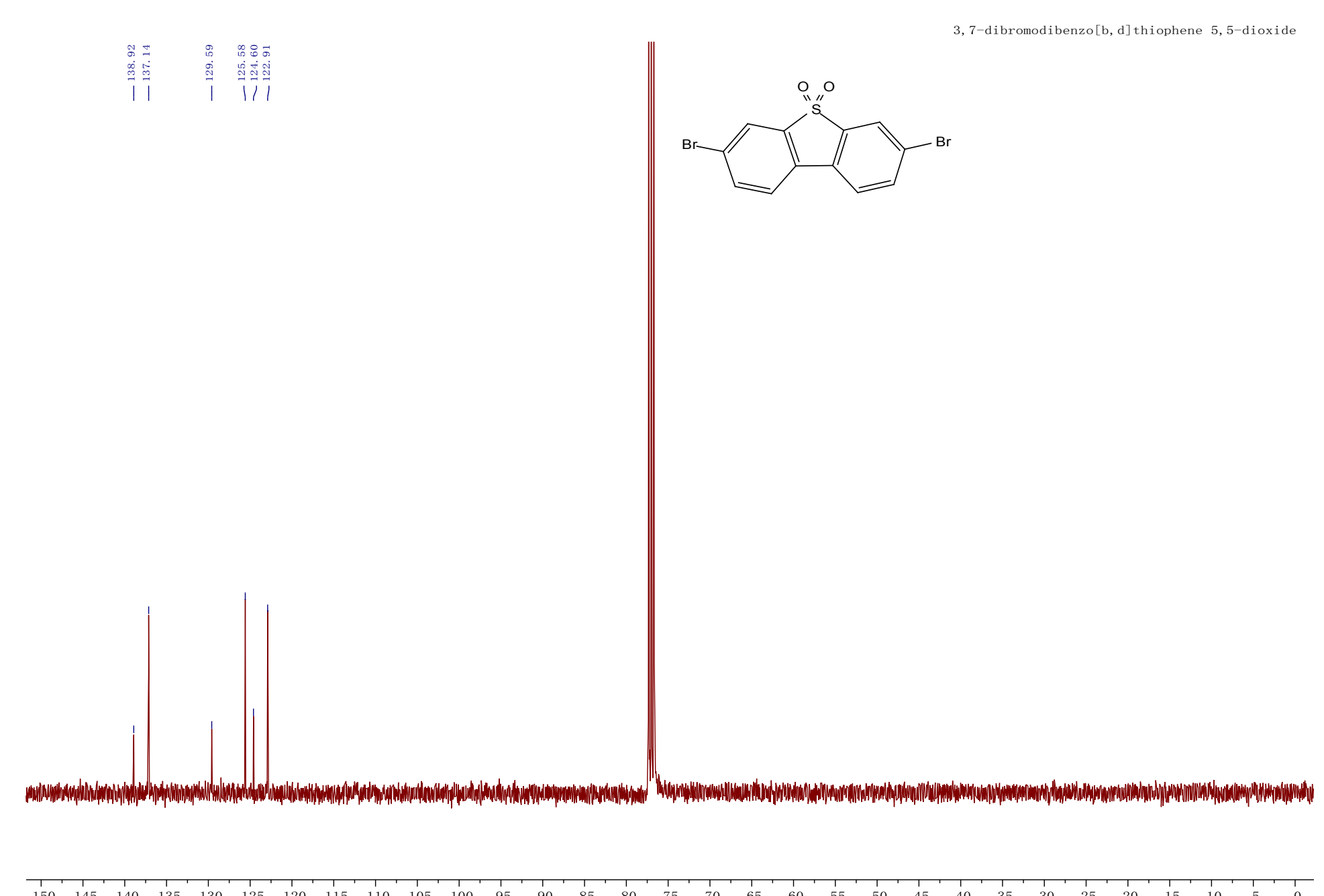




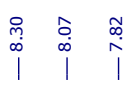

3,7-bis(4,4,5,5-tetramethyl-1,3,2-dioxaborolan-2-yl)dibenzo[b,d]thiophene 5,5-dioxide

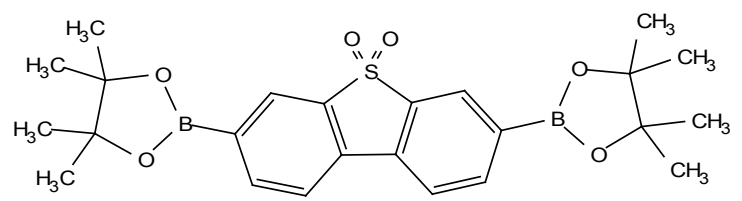

$51+1$

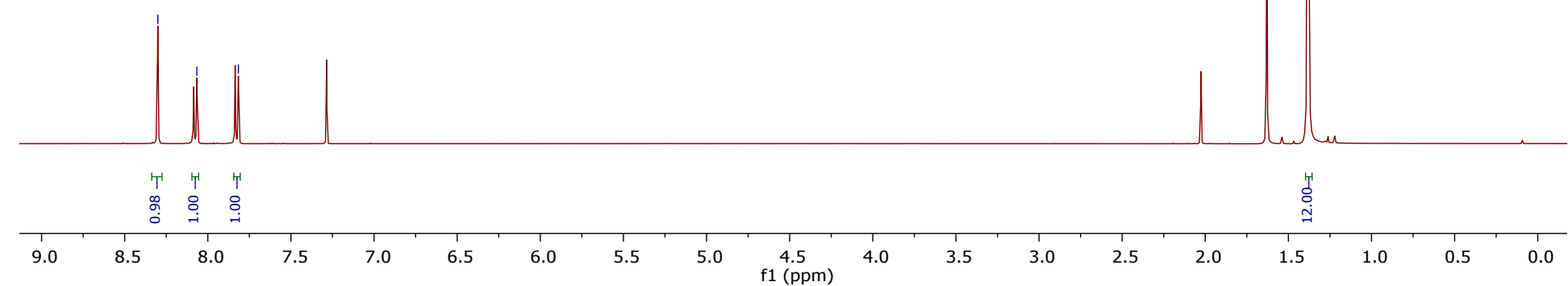




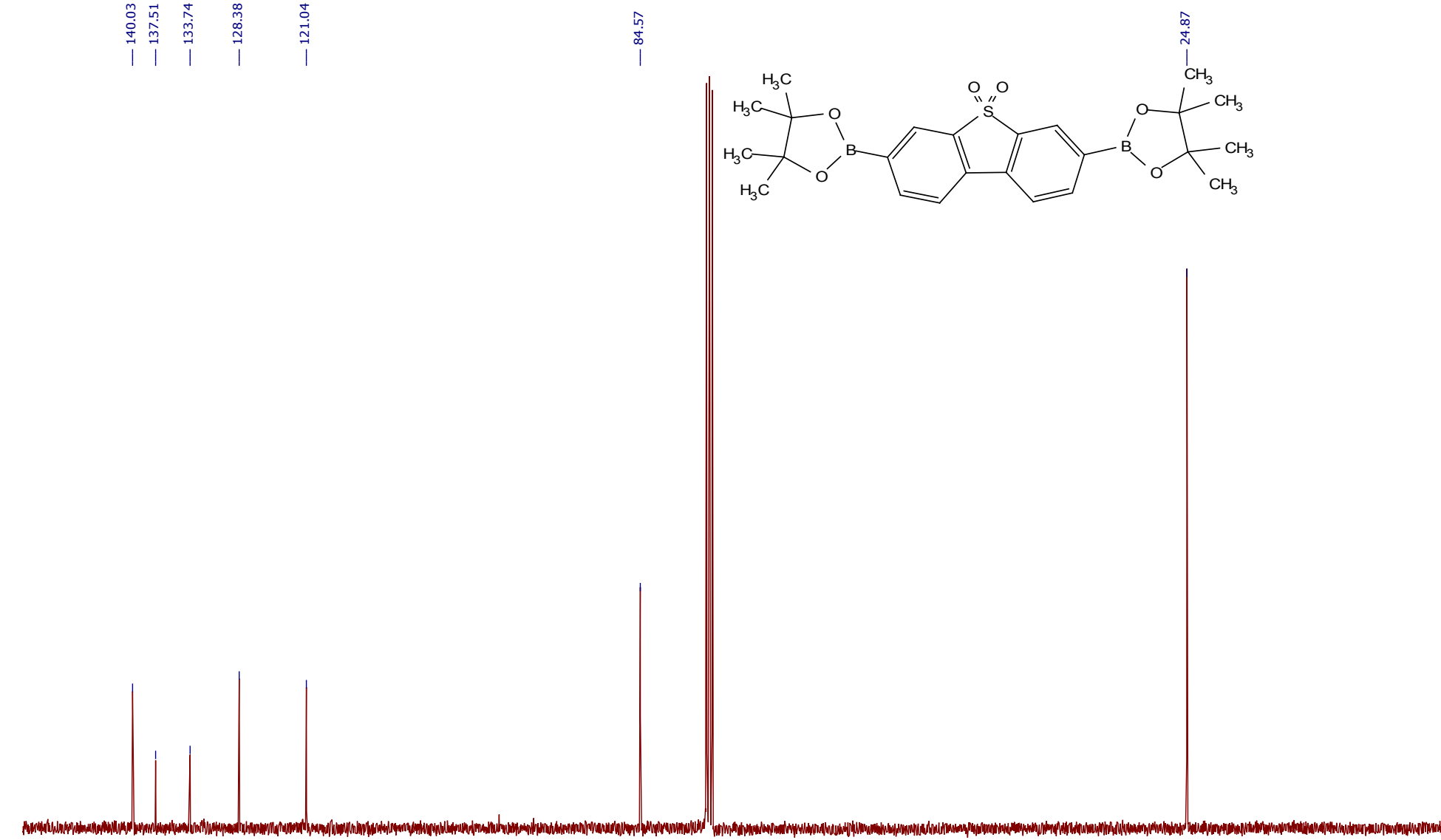

$\begin{array}{llllllllllllllllllllllllllllllllllllllllllll}150 & 145 & 140 & 135 & 130 & 125 & 120 & 115 & 110 & 105 & 100 & 95 & 90 & 85 & 80 & 75 & 70 & 65 & 60 & 55 & 50 & 45 & 40 & 35 & 30 & 25 & 20 & 15 & 10 & 5 & 0\end{array}$ 


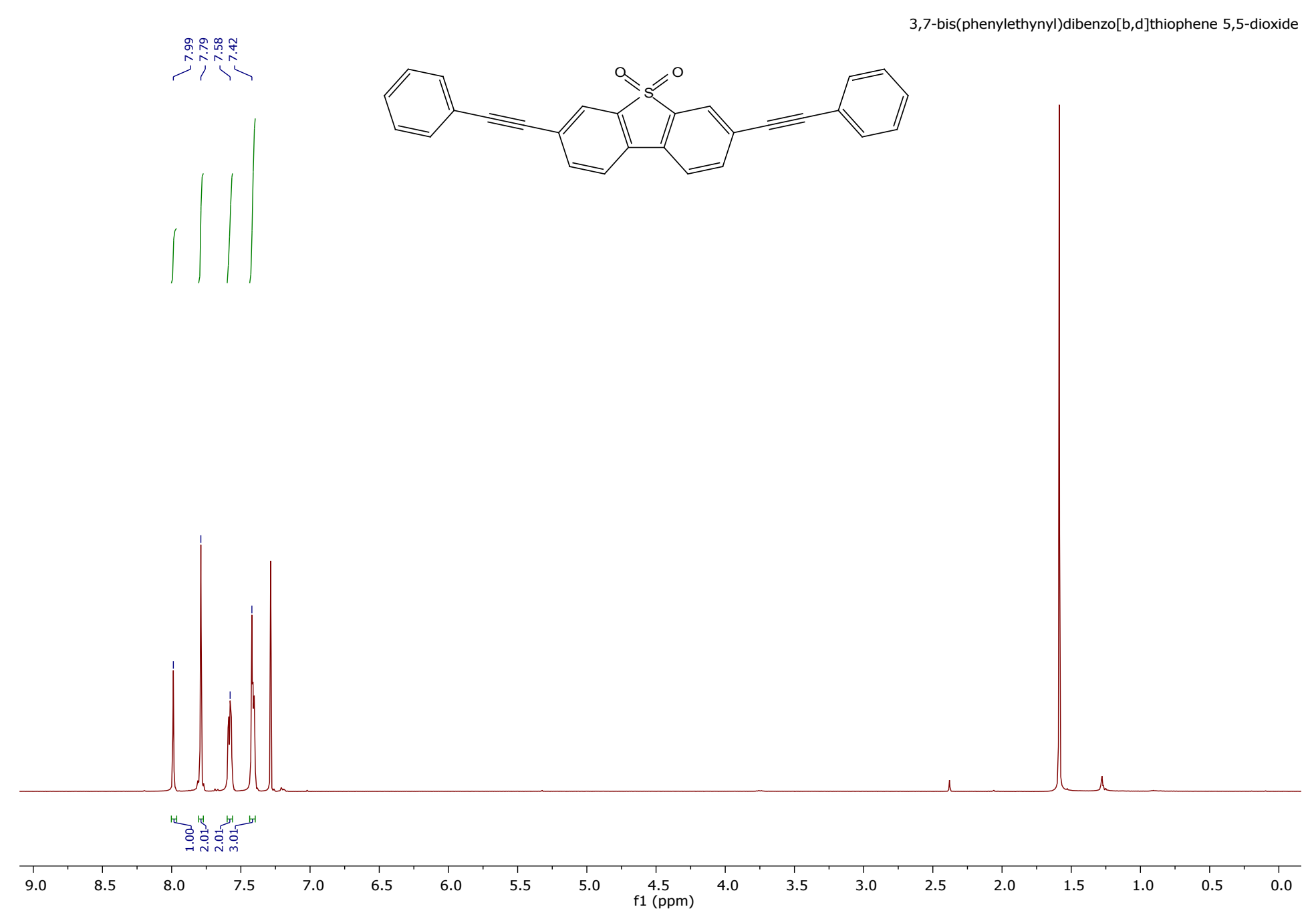




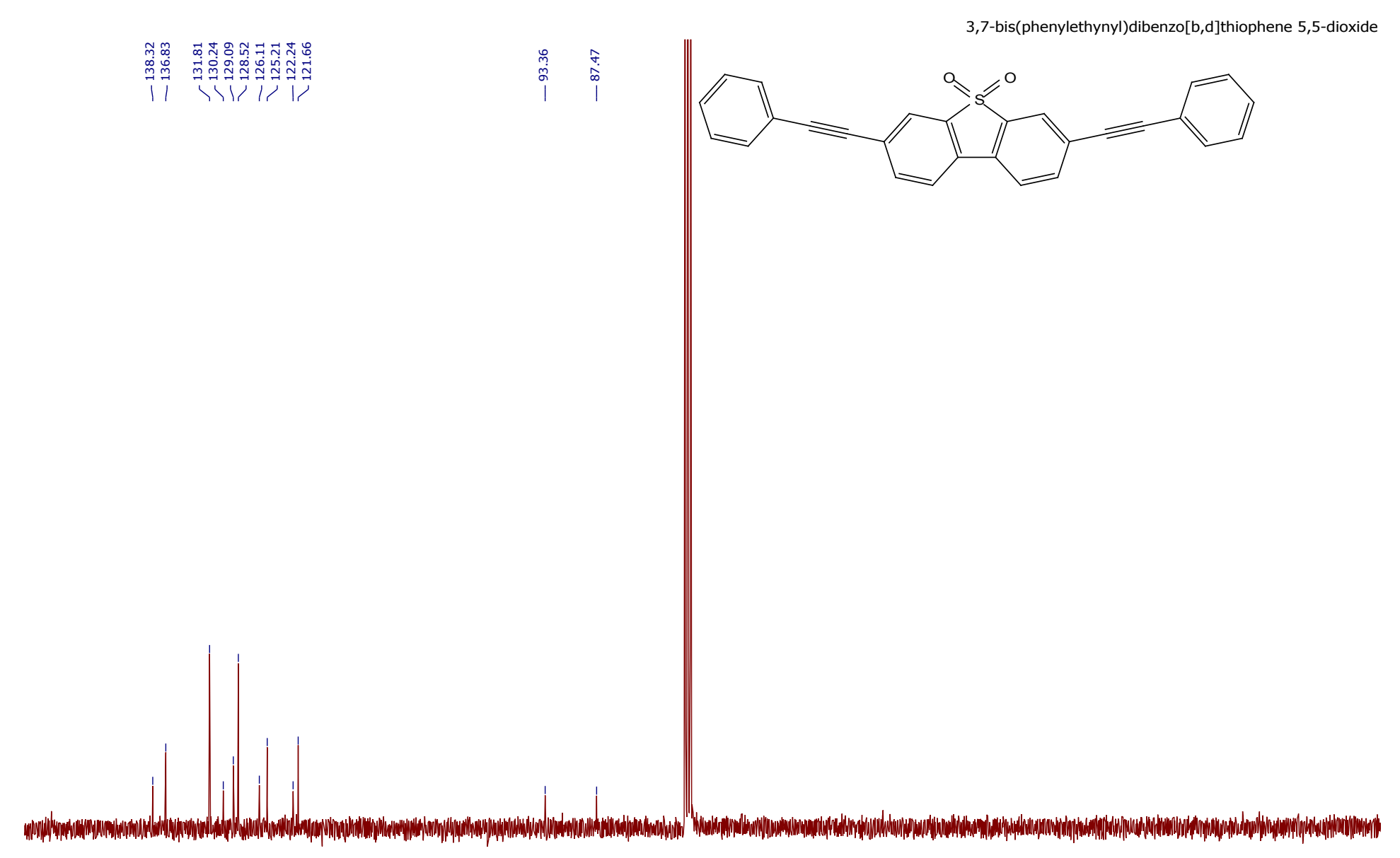

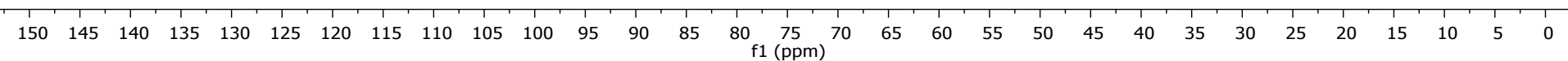

